\title{
Root iTRAQ protein profile analysis of two Citrus species differing in aluminum- tolerance in response to long-term aluminum-toxicity
}

Huan-Xin Jiang ${ }^{1,2}$, Lin-Tong Yang ${ }^{1,3}$, Yi-Ping Qi ${ }^{4}$, Yi-Bin Lu ${ }^{1,3}$, Zeng-Rong Huang ${ }^{1,3}$ and Li-Song Chen ${ }^{1,3,5,6^{*}}$

\begin{abstract}
Background: Limited information is available on aluminum (Al)-toxicity-responsive proteins in woody plant roots. Seedlings of 'Xuegan' (Citrus sinensis) and 'Sour pummelo' (Citrus grandis) were treated for 18 weeks with nutrient solution containing 0 (control) or $1.2 \mathrm{mM} \mathrm{AlCl} 3 \cdot 6 \mathrm{H}_{2} \mathrm{O}(+\mathrm{Al})$. Thereafter, we investigated Citrus root protein profiles using isobaric tags for relative and absolute quantification (iTRAQ). The aims of this work were to determine the molecular mechanisms of plants to deal with Al-toxicity and to identify differentially expressed proteins involved in Al-tolerance.
\end{abstract}

Results: C. sinensis was more tolerant to Al-toxicity than C. grandis. We isolated 347 differentially expressed proteins from + Al Citrus roots. Among these proteins, 202 (96) proteins only presented in C. sinensis (C. grandis), and 49 proteins were shared by the two species. Of the 49 overlapping proteins, 45 proteins were regulated in the same direction upon Al exposure in the both species. These proteins were classified into following categories: sulfur metabolism, stress and defense response, carbohydrate and energy metabolism, nucleic acid metabolism, protein metabolism, cell transport, biological regulation and signal transduction, cell wall and cytoskeleton metabolism, and jasmonic acid (JA) biosynthesis. The higher Al-tolerance of $C$. sinensis may be related to several factors, including: (a) activation of sulfur metabolism; (b) greatly improving the total ability of antioxidation and detoxification; (c) up-regulation of carbohydrate and energy metabolism; (d) enhancing cell transport; (e) decreased (increased) abundances of proteins involved in protein synthesis (proteiolysis); ( $f$ ) keeping a better balance between protein phosphorylation and dephosphorylation; and $(g$ ) increasing JA biosynthesis.

Conclusions: Our results demonstrated that metabolic flexibility was more remarkable in C. sinenis than in C. grandis roots, thus improving the Al-tolerance of $\mathrm{C}$. sinensis. This provided the most integrated view of the adaptive responses occurring in Al-toxicity roots.

Keywords: Aluminum-toxicity, Citrus, iTRAQ, Proteomics, Root, Sulfur metabolism

\footnotetext{
*Correspondence: lisongchen2002@hotmail.com

${ }^{1}$ Institute of Plant Nutritional Physiology and Molecular Biology, Fujian

Agriculture and Forestry University, Fuzhou 350002, China

${ }^{3}$ College of Resource and Environmental Science, Fujian Agriculture and

Forestry University, Fuzhou 350002, China

Full list of author information is available at the end of the article
} 


\section{Background}

In many acidic soils through the tropics and subtropics, aluminum (Al)-toxicity is a major factor limiting crop productivity. Approximately $30 \%$ of the world's total land area is acidic [1]. Furthermore, the acidity of the soils is increasing due to the environmental problems including some farming practices and acid rain [2]. When soil $\mathrm{pH}$ is less than 5.0, toxic forms of $\mathrm{Al}$ (mainly $\mathrm{Al}^{3+}$ ) are solubilized into the soil solution and accumulate to high concentration that rapidly inhibits plant root growth by damaging the roots functionally and structurally, subsequently decreasing nutrient and water uptake, eventually resulting in poor crop growth and productivity $[3,4]$. A traditional strategy is to raise soil $\mathrm{pH}$ by application of lime, thus alleviating Al-toxicity; however, the approach is both costly and ecologically unsound from the long-term point of view. A more efficient strategy is to breed Al-tolerant crop cultivars. Fortunately, plants display wide variation in their ability to deal with $\mathrm{Al}$-toxicity. Variation in Al-tolerance makes it possible to breed tolerant cultivars. The success of breeding programs relies on an understanding of the physiological, biochemical and molecular mechanisms that plants tolerate Al-toxicity. Since biological processes are ultimately controlled by proteins, identification and characterization of Al-tolerant proteins will not only increase our understanding of the molecular mechanisms on plant Al-tolerance, but also will provide new information that researchers will use to screen and breed crop cultivars suited for acidic soils with higher active Al.

During the long-term evolutionary process, higher plants have evolved two main strategies (i.e., external detoxification mechanisms and internal detoxification mechanisms) that enable them to tolerate high level of soil active $\mathrm{Al}[2,3]$. Although several mechanisms for the external detoxification (i.e., formation of non-toxic $\mathrm{Al}$ chelates with $\mathrm{Al}$ ligands released by roots, alkalinization of the rhizosphere, modified cell wall and redistribution of $\mathrm{Al}$ ) have been suggested, the $\mathrm{Al}$-induced secretion of organic acid anions such as citrate, malate and oxalate from roots is the most-studied mechanism of Al-tolerance in higher plants $[2,5]$. Genes involved in $\mathrm{Al}$-induced root secretion of citrate and malate have been isolated from wheat (ALMT1), sorghum (SbMATE) and barley (HvMATE). Transgenic plants over-expressing these genes displayed increased $\mathrm{Al}$-activated root secretion of malate and/or citrate and enhanced Al-tolerance [2, 5, 6]. Internal detoxification is mainly reached by both complexation and sequestration of $\mathrm{Al}$ [6].

Gene expression networks revealed by transcriptomics offer us the opportunity to understand the molecular mechanisms of plant Al-toxicity and -tolerance. Although
Al-induced changes in gene expressions have been examined in some detail [7-9], limited data are available on Al-toxicity-responsive proteins in higher plants. Alteration of plant proteins is an inevitable process to deal with environmental stresses including Al-toxicity $[4,10,11]$. Proteomics is a very powerful tool for analyzing the functions of the plant proteins. Abundance of a protein is not only regulated at transcriptional, but also at translational and post-translational levels. Therefore, proteomic analysis may provide more accurate and comprehensive data than what genomic studies can provide. Recently, there were several studies reporting Alinduced changes in plant proteins using two-dimensional gel electrophoresis (2-DE) or isobaric tags for relative and absolute quantification (iTRAQ) technique. Study with Al-tolerant rice (Oryza sativa) cultivar showed that root abundances of copper/zinc superoxide dismutase $(\mathrm{Cu} / \mathrm{Zn} \mathrm{SOD}), \mathrm{S}$-adenosylmethionine synthetase, cysteine (Cys) synthase, 1-aminocydopropane-1-carboxylate oxidase (ACC oxidase), glutathione S-transferase (GST) increased in response to Al-toxicity, and that Cys synthase might play a key role in Al-tolerance [4]. In Al-tolerant soybean cultivar roots, $\mathrm{Al}$ induced the production of heat shock proteins (HSPs), GST, chalcone-related synthetase, GTP-binding protein, and ATP Binding Cassette (ABC) transporter ATP-binding protein [12]. Duressa et al. [13] observed that $\mathrm{Al}$ resulted in a distinct protein profile changes in Al-tolerant and $\mathrm{Al}$-sensitive soybean genotypes. In tomato roots, dehydroascorbate reductase (DHAR), glutathione reductase (GR), catalase (CAT), mitochondrial aldehyde dehydrogenase (ALDH), catechol oxidase, quinone reductase, and lactoylglutathione lyase involved in antioxidation and detoxification were induced by $\mathrm{Al}$ [14]. Dai et al. [15] isolated 35 proteins associated with Altolerance in Al-tolerant wild barley XZ16. There were 16 proteins, which were up-regulated in XZ16 roots, but down-regulated or unaltered in both Al-tolerant barley cultivar Dayton and Al-sensitive wild barley XZ61. Oh et al. [16] identified 19 up-regulated protein spots such as S-adenosylmethionine, oxalate oxidase (OXO), malate dehydrogenase $(\mathrm{MDH})$, Cys synthase, ascorbate peroxidase (APX) and 28 down-regulated protein spots such as HSP 70, O-methytransferase 4, enolase and amylogenin in $+\mathrm{Al}$ wheat roots. Wang et al. [11] identified 106 Al-toxicity-responsive proteins from Al-sensitive and -tolerant rice roots. They observed that glycolysis/gluconeogenesis was the most significantly up-regulated biochemical process in Al-toxic roots. To our knowledge, data available on the effects of Al-toxicity on root proteomics of woody plants are very limited.

Citrus spp. are cultivated mainly in acidic and strong acidic soils such as red soil, yellow soil or lateritic red soil. In 2011, Li et al. [17] investigated the $\mathrm{pH}$ of 319 'Guanximiyou' pummelo (Citrus grandis) orchard soils 
from Pinghe county, Zhangzhou, China. Up to $90 \%$ of soils had a lower $\mathrm{pH}$ than 5.0. Low $\mathrm{pH}$ and high $\mathrm{Al}$ are the factors contributing to poor Citrus growth and shortened lifespan of trees [18]. In this study, we compared Al-induced quantitative and qualitative changes in proteomes that occurred in roots of Al-tolerant Citrus sinensis and $\mathrm{Al}$-sensitive $C$. grandis seedlings [19] using iTRAQ technique in order to identify differentially expressed proteins involved in Al-tolerance and to understasnd the molecular mechanisms of plants to deal with Al-toxicity.

\section{Results}

\section{Plant growth and Al concentration in roots}

As shown in Fig. 1a-c, $1.2 \mathrm{mM}$ Al-treated $(+\mathrm{Al}) C$. grandis seedings displayed decreased whole plant and shoot dry weights (DWs) and unchanged root DW, compared with controls, while Al-toxicity did not significantly affect $C$. sinensis whole plant, shoot and root DWs. There was no significant difference in whole plant, shoot and root DWs between the two species at each given $\mathrm{Al}$ treatment. Root concentration of $\mathrm{Al}$ was higher in $+\mathrm{Al}$ seedlings than controls, while did not significantly differ between the two species at each given $\mathrm{Al}$ treatment (Fig. 1d).

It is worth mentioning that $1.2 \mathrm{mM} \mathrm{Al}$ treatment decreased $C$. grandis root DW, but had no influence on C. sinensis root DW and that Al-toxicity-induced decreases in whole plant and shoot DWs were more severe in $C$. grandis than in C. sinensis seedlings, when $20 \mu \mathrm{M} \mathrm{H}_{3} \mathrm{BO}_{3}$ in nutrient solution was replaced by $2.5 \mu \mathrm{M} \mathrm{H}_{3} \mathrm{BO}_{3}$. In addition, $\mathrm{Al}$ concentration was not lower in C. sinensis than in C. grandis roots at each given $\mathrm{Al}$ level (Additional file 1).

\section{Primary data analysis and protein identification}

A total of 333528 spectra were produced from the iTRAQ experiment using control and Al-toxic C. sinensis and C. grandis roots as materials. By analyzing these spectra, we identified 42532 known spectra, 38369 unique spectra, 15191 peptides, 14266 unique peptides and 4160 proteins, respectively (Fig. $2 \mathrm{a}$ ). The number of proteins in the genome is 46147 (http://phytozome.jgi.doe.gov/pz/portal.html\#!info?alias=Org_Csinensis), due to the reasons of samples and technical restrain, 4160 identified proteins in current proteomic research is nor$\mathrm{mal}$ in plants. Protein number decreased with increased number of peptides that matched to proteins, but over $67 \%$ of the proteins (i.e., 2789 proteins) included at least two peptides (Fig. 2b).

Both protein mass distribution and distribution of sequence coverage were summarized in Fig. $2 \mathrm{c}$ and $\mathrm{d}$. Proteins with $20-30 \mathrm{kDa}$ and $30-40 \mathrm{kDa}$ were at the most abundant, followed by proteins with $40-50 \mathrm{kDa}$ and 50-60 kDa. Protein number decreased with increased sequence coverage.

Figure 2e shows the distribution of peptide length in Citrus roots. Less than $8.7 \%$ of all peptides are $\geq 20$ amino acid residues and $80.6 \%$ are between 8 and 17 residues.

\section{Differentially expressed proteins by iTRAQ}

In this study, a protein was considered differentially expressed when the protein had both a $\log 2$ foldchange of more than 1.5 and a $P$-value of less than 0.05. Based on the two criteria, 251 differentially

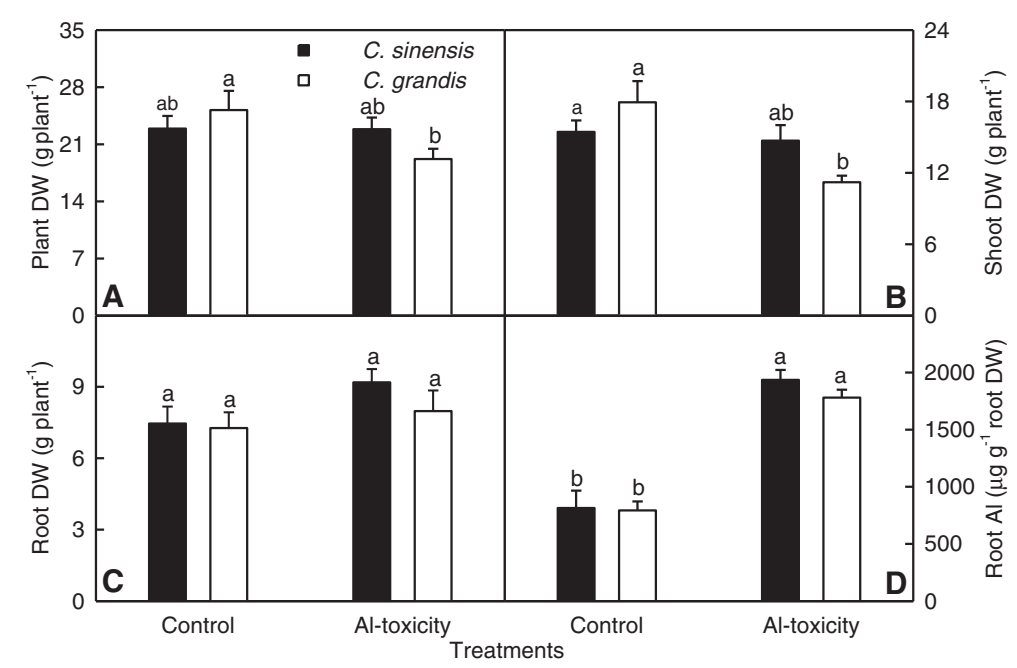

Fig. 1 Effects of Al-toxicity on plant growth and root Al concentration in C. sinensis and C. grandis seedlings. a-c Whole plant, shoot and root dry weights (DWs). $\mathbf{d}$ Root Al concentration. Bar represents the mean \pm SE ( $n=10$ for plant DW or 4 for Al concentration). Differences among four treatment combinations were analyzed by 2 (species) $\times 2$ (Al levels) ANOVA. Different letters above the bars indicate a significant difference at $P<0.05$ 


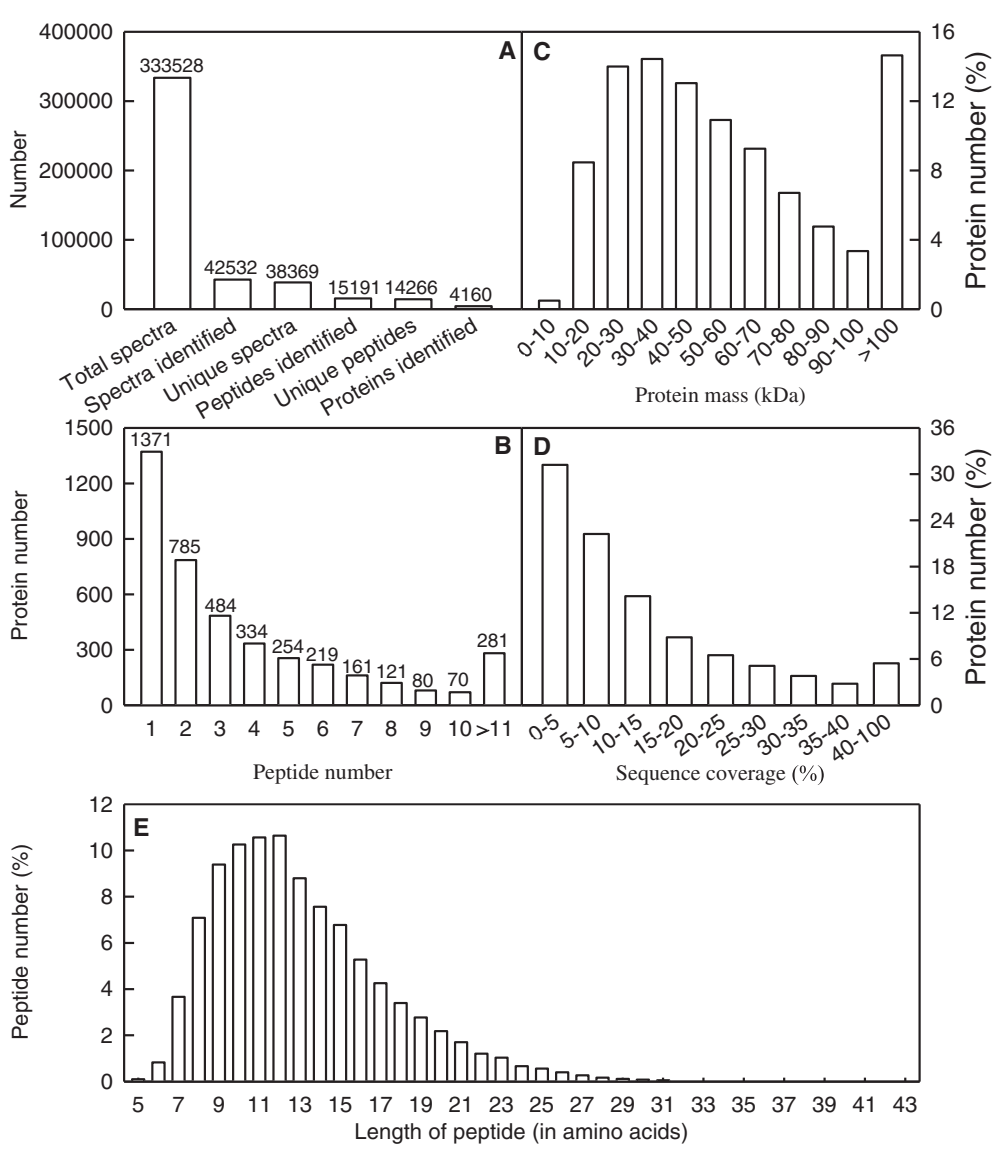

Fig. 2 Spectra, peptides and proteins identified from iTRAQ proteomics by searching against $C$. sinensis database (a), number of peptides that match to proteins using MASCOT (b), protein mass distribution (c), distribution of protein sequence coverage (d), and distribution of peptide length (e)

expressed proteins were detected in $+\mathrm{Al} C$. sinensis roots, $120(47.8 \%)$ of which displayed increased and 131 (52.2 \%) displayed decreased abundance. These proteins were related to sulfur $(\mathrm{S})$ metabolism, stress and defense response, carbohydrate and energy metabolism, nucleic acid metabolism, protein metabolism, cell transport, biological regulation and signal transduction, cell wall and cytoskeleton metabolism, jasmonic acid (JA) biosynthesis and others (Additional file 2 and Fig. 3a). In $+\mathrm{Al} \mathrm{C}$. grandis roots, we isolated 44 (30.3 \%) up- and 101 (69.7 \%) downregulated proteins, which were grouped into following functional categories: S metabolism, stress and defense response, carbohydrate and energy metabolism, nucleic acid metabolism, protein metabolism, cell transport, biological regulation and signal transduction, cell wall and cytoskeleton metabolism and others (Additional file 2 and Fig. 3b). Figures 4 and 5 showed Al-induced alterations of proteins involved in $\mathrm{S}$ metabolism in C. sinensis and $C$. grandis roots and JA biosynthesis in C. sinensis roots, respectively.

As shown in Fig. 3c, a total of 347 differentially expressed proteins were detected from $+\mathrm{Al} C$. grandis and C. sinensis roots. Among these proteins, 202 (96) proteins only presented in C. sinensis (C. grandis) and 49 proteins were shared by the two species. Of the 49 overlapping proteins, 45 proteins were regulated in the same direction upon $\mathrm{Al}$ exposure in the both species, the remaining four proteins were regulated in the opposite direction.

\section{qRT-PCR analysis of genes for some differentially expressed proteins}

To valuate the correlation between mRNA and protein levels, we assayed the expression levels of genes for 10 differentially expressed proteins (i.e., gi|281426908, gi|75 154467, gi|1171937, gi|34099833, gi|378724814, gi|212 64375, gi|301341860, gi|380863042, gi|110007377 and gi|3913733) in C. sinensis and C. grandis roots (Fig. 6). For $C$. grandis roots, the expression levels of nine genes matched well with our iTRAQ data, while only four genes matched well with the iTRAQ data for $C$. sinensis roots (Additional file 2). Six genes [i.e., gi|1171937, gi|34099833, gi|21264375, gi|301341860, gi|380863042 and gi|3913733) were regulated differentially at transcript and protein levels in the both species. Thus, it is 


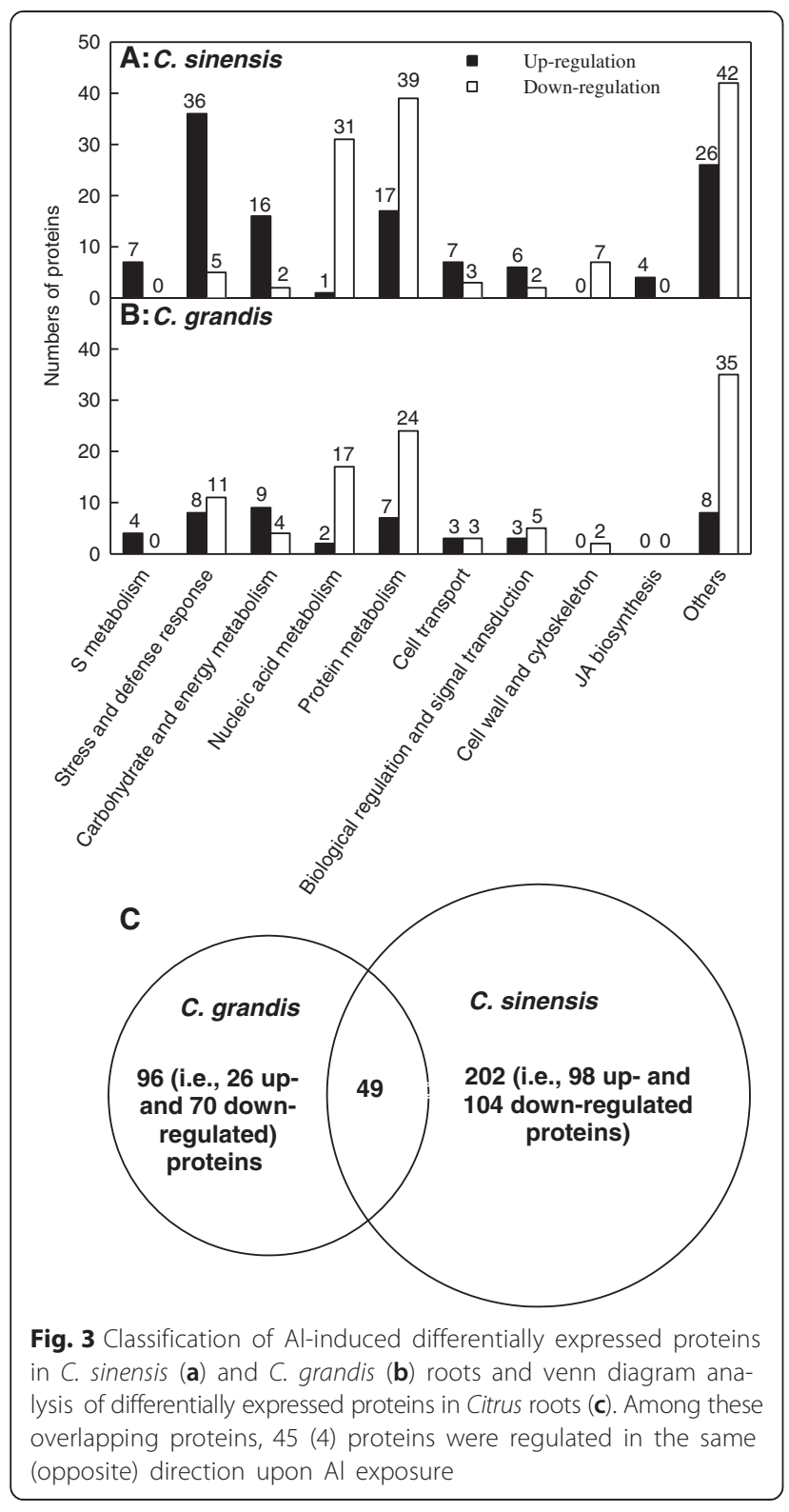

reasonable to assume that the discrepancy between the expression levels of genes and the abundances of the corresponding protein might be caused by post-translational modifications (PTMs).

\section{Discussion}

C. sinensis is more tolerant to Al-toxicity than C. grandis Our results showed that Al-toxicity inhibited C. grandis shoot growth, but had no significant influence on $C$. sinensis growth, and that root $\mathrm{Al}$ concentration did not differ between the two species (Fig. 1). When $20 \mu \mathrm{M}$ $\mathrm{H}_{3} \mathrm{BO}_{3}$ in nutrient solution was replaced by $2.5 \mu \mathrm{M}$ $\mathrm{H}_{3} \mathrm{BO}_{3}, 1.2 \mathrm{mM} \mathrm{Al}$ inhibited C. grandis root and shoot growth, but only significantly inhibited $C$. sinensis shoot growth even though $\mathrm{Al}$ concentration was higher in $\mathrm{Al}$ -
Sulfate

$\downarrow$ ATPS

APS

$\downarrow$ APS reductase

Sulfite

$\downarrow$ Sulfite reductase

Sulfide

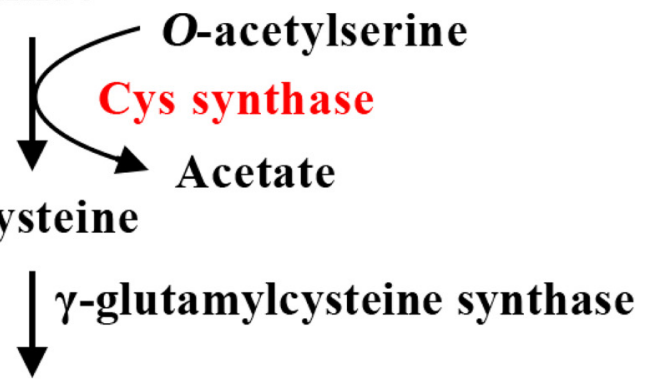

$\gamma$-glutamylcysteine

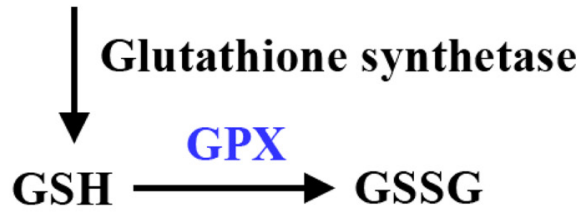

$\downarrow$ GST

\section{R-S-glutathione}

Fig. 4 Al-induced changes in S metabolism in C. sinensis and C. grandis roots. Up-regulated proteins presented in $+\mathrm{Al} C$. sinensis and C. grandis (only in C. sinensis) roots were labeled in red (blue). Abbreviations: APS, adenosine phosphosulphate; GSH, reduced glutathione; GSSG, oxidized glutathione

toxic C. sinensis roots than in Al-toxic C. grandis ones. Futhermore, Al-toxicity-induced inhibition of shoot growth was less severe in $C$. sinensis seedlings than in C. grandis ones (Additional file 1). To conclude, the present work, like that of previous workers $[19,20]$, demonstrates that $C$. sinensis is more tolerant to Altoxicity than C. grandis.

As shown in Additional file 2, we identified 251 differentially expressed proteins from $+\mathrm{Al} C$. sinensis roots, while only 145 differentially expressed proteins 


\section{$\alpha$-linolenic acid}

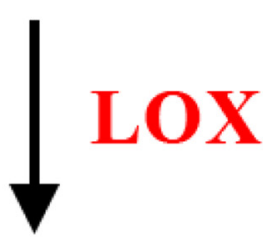

\section{3-HPOT}

AOS

AOC
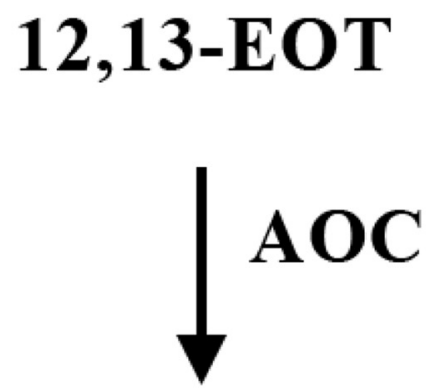

cis-(+)-OPDA

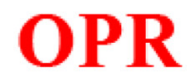

OPC-8

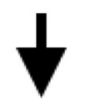

$\downarrow \mathrm{ACX}$

$\downarrow \beta$-oxidation

$$
\text { (+)-7-iso-JA }
$$

Fig. 5 Metabolic scheme of JA biosynthesis in Citrus sinensis roots. Up-regulated proteins in + Al roots were labeled in red. Abbreviations: LOX, lipoxygenase; 13-HPOT, (13S)-hydroperoxyoctadecatrienoic acid; AOS, allene oxide synthase; 12,13-EOT, 12,13-epoxyoctadecatrienoic acid; AOC, allene oxide cyclase; cis-(+)-OPDA; cis-(+)-12-oxophytodienoic acid; OPR, oxophytodienoic acid reductase; OPC-8, 3-oxo-2-(2'(Z)-pentenyl)cyclopentane-1-octanoic acid; ACX, acyl-CoA-oxidase

were identified from $+\mathrm{Al}$ C. grandis roots. This demonstrated that the metabolic flexibility was more remarkable in $C$. sinensis roots than in $C$. grandis ones in response to $\mathrm{Al}$, which may contribute to the higher Al-tolerance of $C$. sinensis.

\section{$\mathrm{S}$ metabolism was up-regulated in Al-treated roots}

$\mathrm{S}$ metabolism is a core pathway for the synthesis of molecules required for some environmental stresses including $\mathrm{Al}[4,10]$. Transgenic plants over-expressing $\mathrm{S}$ metabolism-related genes such as GST and glutathione peroxidase (GPX) displayed enhanced tolerance to Al-toxicity and/or to oxidative stress [21-23]. The upregulation of ATP sulfurylase 1 (ATPS 1) and probable GPX 4 in C. sinensis roots and Cys synthase and GST in C. sinensis and C. grandis roots in response to $\mathrm{Al}$ (Additional file 2 and Fig. 4) indicated that S metabolism was enhanced in Al-treated roots. This agrees with the reports that $\mathrm{S}$ metabolism-related enzymes (i.e. GST, GPX, ATPS and Cys synthase) were induced by various stresses including $\mathrm{Al}[1,4,16,24]$, and that $\mathrm{Al}$ toxicity increased rice root concentrations of reduced glutathione (GSH) + oxidized glutathione (GSSG) and GSH [4] and Citrus leaf concentrations of GSH and GSSG [25]. Thus, S metabolism may play a role in response to Al-toxicity by the synthesis of molecules required for $\mathrm{Al}$ detoxification and confer $\mathrm{Al}$-tolerance in both C. grandis and C. sinensis, particularly in the latter.

\section{Proteins involved in stress and defense response}

Increased reactive oxygen species (ROS) level is commonly presumed to be a major component of Al-toxicity. Here, the abundances of six antioxidant enzymes (i.e., gi|262192812, gi|378724814, gi|255587906, gi|218138216, gi|110007377 and gi|195548074) increased in $+\mathrm{Al} C$. sinensis roots (Additional file 2). Al-induced up-regulation of antioxidant enzymes has also been observed in Al-toxic roots of tomato [14] and rice [11]. However, we only identified one up-regulated (i.e., gi|255549391) and two downregulated (gi|225626263 and gi|89276748) antioxidant enzymes from $+\mathrm{Al} \mathrm{C.} \mathrm{grandis} \mathrm{ones} \mathrm{(Additional} \mathrm{file} \mathrm{2).}$ Germin and germin-like proteins (GLPs), which have different enzyme functions such as OXO and SOD, play a role in various abiotic stresses [26, 27]. Study showed that $\mathrm{Al}$-induced OXO expression in wheat roots could be involved in detoxification mechanism 


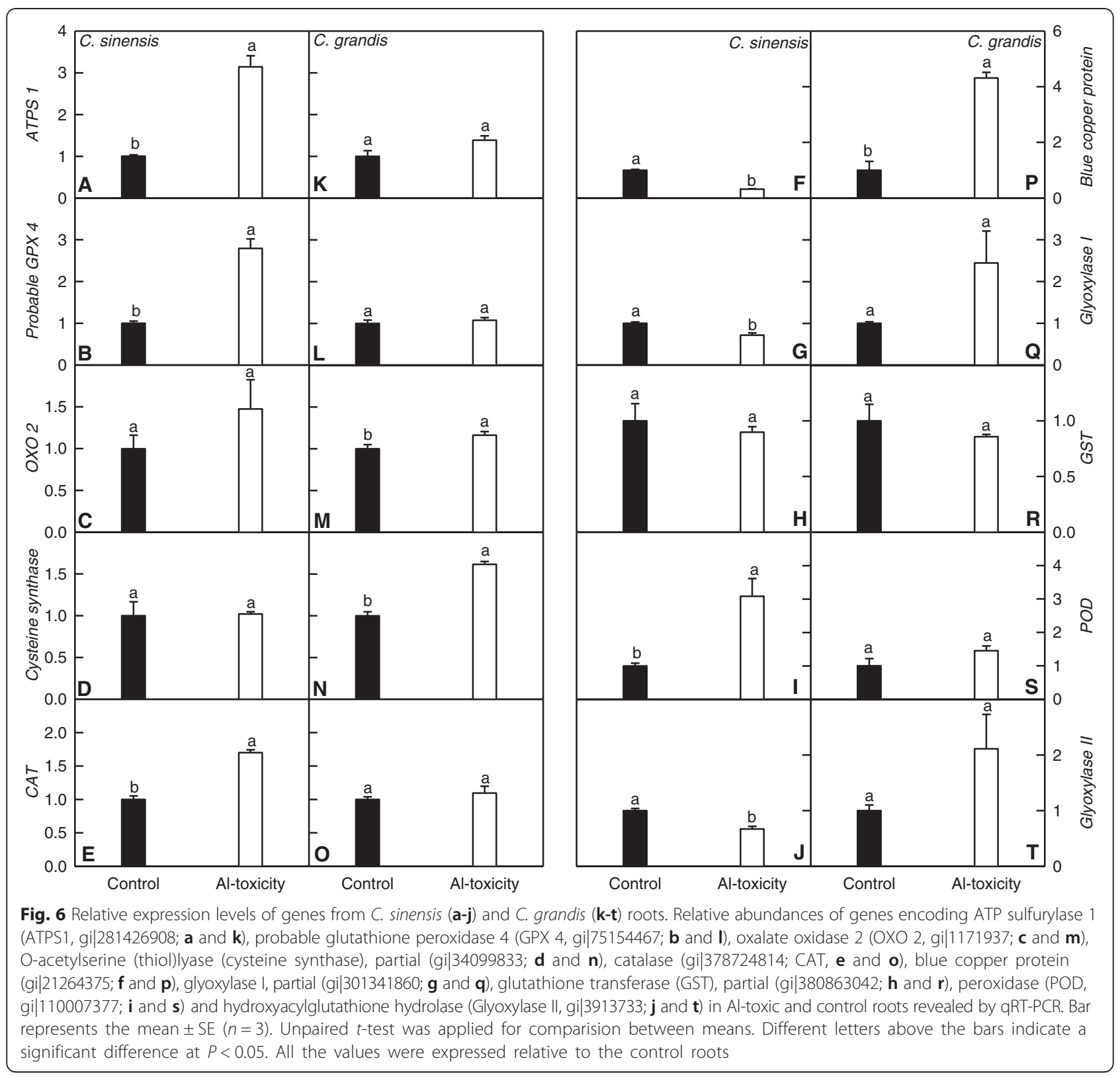

[28]. Thus, Al-induced increase in the levels of OXO 2 and seven GLPs in C. sinensis roots might play a role in Al-tolerance of $C$. sinensis. However, we only isolated an up-regulated $\mathrm{OXO} 2 \mathrm{in}+\mathrm{Al} C$. grandis roots (Additional file 2). Also, we isolated four upregulated proteins [i.e., blue copper protein $(\mathrm{BCP})$, CBS domain-containing protein CBSX3, thioredoxin $\mathrm{m}$ (mitochondrial)-type, and plastid-lipid associated protein] involved in ROS scavenging from $+\mathrm{Al} C$. sinensis roots, while only one up-regulated $\mathrm{BCP}$ (gi|21264375) and one down-regulated BCP (gi|2493318) were isolated from $+\mathrm{Al}$ C. grandis roots (Additional file 2). To sum up, the abundances of proteins involved in ROS detoxification were greatly enhanced in $+\mathrm{Al}$ C. sinensis roots, but were less affected in $+\mathrm{Al}$ C.grandis ones.

In addition to ROS formation, Al-toxicity also results in overproduction of aldehydes and methylglyoxal (MG) through the activation of various enzymatic and nonenzymatic reactions. As expected, the abundances of ALDH $7 \mathrm{~b}$ involved in the detoxification of the aldehydes, alcohol dehydrogenase (ADH)-like 2, which catalyzes the inter-conversions between alcohols and aldehydes, and glyoxalase (Gly) I and Gly II involved in the detoxification of MG were enhanced in Al-toxic C. sinensis roots, while the abundance of the probable aldo-keto reductase (AKR) 1 involved in the detoxification of 
lipid peroxidation- and/or glycolysis-derived reactive carbonyls [i.e., malondialdehyde (MDA), 4-hydoxynonenal and $\mathrm{MG}$ ] was down-regulated in $+\mathrm{Al} C$. grandis roots (Additional file 2). Thus, the ability of aldehydes and MG detoxification might be enhanced in $+\mathrm{Al} \mathrm{C}$. sinensis roots, thus contributing its higher $\mathrm{Al}$-tolerance, but down-regulated in $+\mathrm{Al} C$. grandis roots.

The up-regulation of two HSPs (i.e., gi|460411113 and gi|211906498) in $+\mathrm{Al} \mathrm{C.} \mathrm{sinensis} \mathrm{roots} \mathrm{(Additional} \mathrm{file} \mathrm{2)}$ agrees with the report that two protein spots of dnaK-type molecular chaperone hsc70.1 (At5g02500) in Al-tolerant Arabidopsis ecotype increased in response to Al-toxicity [29], and that the abundance of HSP (LOC_Os06g50300) increased only in Al-tolerant rice roots [11].

Dehydrins, or group 2 LEA (late embryogenesis abundant) proteins, can function as antioxidants, ion sequestrants, or metal ion transporters in plant phloem sap [30]. Al-induced up-regulation of desiccation-related protein $\mathrm{PCC} 13-62$ in $+\mathrm{Al} C$. sinensis roots (Additional file 2) agrees with the report that root expression level of gene encoding desiccated-related protein under Alstress was higher in Al-tolerant soybean genotype than in Al-sensitive one [31]. However, Al-toxicity decreased the levels of LEA14-A in C. sinensis roots (Additional file 2).

We isolated seven up-regulated (i.e., gi|131026, gi|25 5587430, gi|21542143, gi|75163188, gi|147721660, gi|73 88028 and gi|75115690) and one down-regulated (i.e., gi|190613877) pathogenesis-related (PR) proteins from $+\mathrm{Al}$ C. sinensis roots, four down-regulated (i.e., gi|19 0613877, gi|288557882, gi|21542144 and gi|332319679) and one up-regulated (i.e., gi|75115690) PR proteins from $+\mathrm{Al}$ C. grandis ones. Al-induced increase in Snorcoclaurine synthase (gi|75115690) was higher in $C$. sinensis than in C. grandis roots. Generally speaking, Al-toxicity increased the abundances of PR proteins in C. sinensis roots and decreased their levels in C. grandis roots (Additional file 2). This agrees with the reports that PR-10 protein was highly up-regulated at the transcriptional and translational levels in Al-tolerant soybean cultivar roots [12], that root PR Bet v I family protein (LOC_Os03g18850) were expressed at higher level in the tolerant rice cultivar than in the sensitive one [11], and that the expression levels of several PR genes were higher in Al-tolerant soybean genotype roots than in $\mathrm{Al}$-sensitive ones [31]. Thus, the up-regulation of $\mathrm{PR}$ proteins in $+\mathrm{Al}$ C. sinensis roots might contribute to its Al-tolerance.

Harpin proteins can lead to multiple responses in plants, such as systemic acquired resistance, hypersensitive response, and enhancement of growth and drought tolerance. Over-expression of a harpin-encoding gene in rice increased drought tolerance through $\mathrm{ABA}$ signaling [32]. Activated harpin binding protein-1 (HrBP1) can act upstream of the salicylic acid (SA), JA, and ethylene signaling pathways in plant cells [33]. The up-regulation of $\mathrm{HrBP} 1 \mathrm{in}+\mathrm{Al}$ C. sinensis roots might play a role in $\mathrm{Al}-$ tolerance through acting those signaling pathways.

To conclude, the total ability of antioxidation and detoxification was greatly enhanced in $+\mathrm{Al} C$. sinensis roots, thus improving the Al-tolerance of $C$. sinensis.

\section{Proteins involved in carbohydrate and energy metabolism}

Rapid turnover rate of fine roots requires systematic rebuilding of tissues, which is associated with a high reduced carbon cost. Building new root biomass not only requires carbon skeletons to produce cellulose, lignin and other structural compounds, it also requires metabolic energy (growth respiration). Under stress conditions, the demand may increase owing to initiation of response mechanisms and secondary metabolism [34]. Thus, carbohydrate and energy metabolism might be enhanced in Al-treated roots to maintain the primary metabolic pathways and the carbohydrate balance. As expected, all the 18 differentially expressed proteins involved in carbohydrate metabolism were up-regulated in $+\mathrm{Al} \mathrm{C}$. sinensis roots except for two proteins (i.e., gi|75191271 and gi|1351359; Additional file 2). Wang et al. [11] observed that glycolysis/gluconeogenesis was the most significantly up-regulated biochemical process in rice roots in response to $\mathrm{Al}$, suggesting that the enhancement of root glycolytic/gluconeogenetic pathway might promote Al-tolerance by balancing the level of available energy to prevent intracellular shortage. Based on these results, we concluded that the up-regulation of carbohydrate and energy metabolism in $+\mathrm{Al} C$. sinensis roots was an adaptive response to meet the increased requirement for carbon skeletons and energy. By contrast, we identified four down- and nine upregulated proteins involved in carbohydrate and energy metabolism from $+\mathrm{Al}$ C. grandis roots (Additional file 2). Obviously, Al-induced adaptive responses in carbohydrate and energy metabolism were less pronounced in C. grandis than in C. sinensis roots.

\section{Al-induced inhibition of nucleic acid biosynthesis}

We found that all these differentially expressed proteins related to nucleic acid metabolism in $C$. sinensis and $C$. grandis roots except for protein RAD-like 3 involved in regulation of transcription in the two species and ribonuclease, which catalyzes the degradation of RNA into smaller components in C. grandis, were down-regulated in response to Al-toxicity (Additional file 2), demonstrating that Al-toxicity might impair nucleic acid biosynthesis in $C$. sinensis and C. grandis roots and increased RNA degradation in C. grandis roots. This 
agrees with the report that Al-toxicity decreased the concentrations of RNA and DNA, and increased the activities of deoxyribonuclease and ribonuclease in longan (Dimocarpus longan) leaves [35].

\section{Al-induced alteration in protein metabolism}

As shown in Additional file 2, all the 39 differentially expressed ribosomal proteins involved in mature ribosome assembly and translation processes were downregulated in $+\mathrm{Al}$ C. sinensis (26) and C. grandis (13) roots. In addition, the abundances of two proteins (i.e., casein kinase II regulatory subunit and ribosome biogenesis regulatory protein homolog) involved in translation processes, eukaryotic translation initiation factor 5B-like involved in the initiation phase of eukaryotic translation, and peptidyl-prolyl cis-trans isomerase FKBP15-3 involved in protein folding in C. sinensis roots, and of two proteins (i.e., probable prefoldin subunit 1 and prefoldin subunit, putative) involved in protein folding decreased in response to $\mathrm{Al}$-stress except for peptidyl-prolyl cis-trans isomerase in C. sinensis roots. Therefore, we concluded that Al-toxicity impaired protein biosynthesis in roots. Similar results have been obtained on $\mathrm{Al}$-stressed rice roots [11]. The Al-induced down-regulation of many proteins involved in protein biosynthesis and processing, which are the major consumers of ATP and nutrients, indicated that the translation was reasonably regulated to save energy and nutrients in roots, especially in the Altolerant species. Similar results have been obtained on Alstressed Arabidopsis [36] and rice [11] roots. In addition, the widespread down-regulation of root ribosomal proteins, especially in C. sinensis roots, might indicate a redeployment of resources to meet the greater demands for amino acids in non-ribosomal peptide synthesis of glutathione and phytochelation for $\mathrm{Al}$ complexation. This agrees with the above inference that $S$ metabolism was up-regulated in Al-treated roots, especially in $C$. sinensis roots, and with the reports that Al-toxicity increased rice root concentrations of GSH + GSSG and GSH [4] and Citrus leaf concentrations of GSH and GSSG [25].

Protein degradation not only provides molecular substrates for plant respiration but also initiates adaptive responses to (a)biotic stresses by reallocating nutrients from non-essential areas of metabolism to vital cellular activities [37]. As expected, we isolated 13 up-regulated (i.e., two gi|75099392, gi|470138103, gi|257222598, gi|22 5458529, gi|255538024, gi|332278204, gi|18419649, gi $\mid 4$ 2563538, gi|416767, gi|33347413, gi|163256765 and gi|3 53441090) and one down-regulated (i.e., gi|14549156) proteins in proteiolysis from $+\mathrm{Al} \mathrm{C.} \mathrm{sinensis} \mathrm{roots,} \mathrm{five} \mathrm{up-}$ regulated (i.e., gi|75099392, gi| 75099062, gi|470138103, gi|225458529 and gi|332278204) and two down-regulated (i.e., two gi|14549156 and gi|14549156) proteins in proteolysis from $+\mathrm{Al}$ in C. grandis roots (Additional file 2). Wang et al. [11] found that the abundance of Cys protease (LOC_Os09g39070) and mitochondrial-processing peptidase subunit (LOC_Os03g11410)] were increased in + $\mathrm{Al}$ rice roots, suggesting that $\mathrm{Cys}$ protease might play a role in resisting against toxic $\mathrm{Al}$ because root Cys protease was expressed at a higher level in the tolerant than in the sensitive cultivar when exposed to Al-toxicity. The more widespread up-regulation of protein in proteolysis in $C$. sinensis than in $C$. grandis roots might contribute to higher Al-tolerance of $C$. sinensis.

Inactive proteins (i.e., incorrect folding) and proteins, which are no longer required for cell, are tagged by ubiquitin for proteolysis. Unlike the above protease, the abundances of all the 11 differentially expressed proteins involved in ubiquitination in $C$. sinensis (6) and C. grandis (5) roots decreased in response to Al-toxicity (Additional file 2), meaning that the ubiquitination of some proteins might be impaired in $\mathrm{Al}$-stressed roots.

Six proteins related to amino acid metabolism were altered in $+\mathrm{Al}$ C. sinensis and C. grandis roots (Additional file 2). Al-induced decrease in the abundance of aspartate transaminase in C. sinensis roots implied that Altoxicity might decrease $\mathrm{N}$ metabolism flux, because it is the major enzyme controlling aspartate that is used to transport $\mathrm{N}$ from sources to sinks [38]. This disagrees with the report that Al-toxicity increased aspartate transaminase level in rice roots, especially in Al-tolerant cultivar [11]. In plants, sarcorsine oxidase metabolizes both sarcosine and pipecolate with preferential utilization of the latter as an endogenous substrate [39]. Here, we first isolated up-regulated sacrosine oxidase in $+\mathrm{Al} C$. sinensis roots. Nitrite reductase (NiR) is considered to be a controlling enzyme in plant $\mathrm{NO}_{2}$ assimilation. The upregulation of $\mathrm{NiR}$ in $+\mathrm{Al} C$. sinensis roots agrees with the report that combined treatment of acidity and $\mathrm{Pb}^{2+}$ led to an increase in NiR activity of soybean roots [40]. Phenylalanine ammonia-lyase (PAL) catalyzes the nonoxidative deamination of L-phenylalanine to form transcinnamic acid and a free ammonium ion. We observed that Al-toxicity only affected PAL level in Al-intolerant $C$. grandis roots (Additional file 2). However, Wang et al. [11] showed that Al-toxicity decreased PAL abundance in rice roots, especially in Al-tolerant cultivar. Glutamate decarboxylase (GAD) catalyzes the conversion of glutamate to $\gamma$-aminobutyrate (GABA). Root-specific GAD (GAD1) is essential for sustaining GABA level in Arabidopsis [41]. Therefore, GABA level might be elevated in Al-treated $C$. grandis roots due to enhanced level of putative GAD (Additional file 2). The observed higher level of putative GAD also agrees with the report that rice root $G A D$ was expressed primarily under phosphate deprivation [42]. 


\section{Proteins involved in cell transport}

As shown in Additional file 2, we obtained seven upand three down-regulated proteins in cell transport from $+\mathrm{Al} C$. sinensis roots, and three up- and three down-regulated proteins from $+\mathrm{Al}$ C. grandis roots. $\mathrm{ABC}$ transporter facilitates the movement of S-glutathionylated toxins formed in GST-catalyzed conjugation of GSH to toxins and other substrates across biological membranes [43]. The up-regulation of ABC transporter I family member 17 in $+\mathrm{Al} \mathrm{C}$. sinensis roots agrees with the increased reguirement for the transport of S-glutathionylated toxins due to increased GST level. Al-induced increase in ABC transporter has been observed in soybean roots [12]. In Arabidopsis, a putative $\mathrm{ABC}$ transporter-like protein is required for Al-tolerance [44]. The induction of aquaporin in $+\mathrm{Al} \mathrm{C}$. sinensis roots might be involved in Al-tolerance of $C$. sinensis by regulating the transport of water or micronutrients across cell membranes [45]. However, Wang et al. [11] reported that the abundance of aquaporin PIP2 was down-regulated by ca. $50 \%$ only in Al-tolerant rice cultivar, and that NIP2 in Al-tolerant and -sensitive roots was up-regulated to a similar extent by $\mathrm{Al}$. The upregulation of porin/voltage-dependent anion-selective channel protein in $+\mathrm{Al} C$. sinensis agrees with the report that the abundance of root mitochondrial outer membrane porin 2 (LOC_Os05g45950) increased in Altolerant rice cultivar when exposed to Al-toxicity, and decreased in Al-sensitive cultivar [11]. Plasma membrane $\mathrm{H}^{+}$-ATPase has an important role in plant response to nutrient and environmental stresses, such as salt stress, Alstress, $\mathrm{P}$ and $\mathrm{K}$ deficiencies [46]. Mitochondrial ADP/ATP carrier plays a central role in aerobic cell energetics by providing the ATP generated by oxidative phosphorylation to the cytosol [47]. Sec61, an endoplasmic reticulum (ER) membrane protein translocator, participates in the translocation of newly-synthesized proteins into the lumen of the ER. The hydrolysis of the signal peptide for newlysynthesized proteins is carried out by specific proteases called signal peptidases located on the luminal side of ER. The removal of the signal peptide is crucial for the maintenance of ER homeostasis [48]. The induction of protein transport protein Sec61 subunit $\beta$ in $+\mathrm{Al} C$. sinensis roots might provide an adaptive response by maintaining ER homeostasis. However, its abundance decreased in $+\mathrm{Al} \mathrm{C}$. grandis roots. By contrast, three proteins (i.e., gi|28380129, gi|289584365 and gi|225463791) in protein transport decreased in $+\mathrm{Al} C$. sinensis roots. Besides their role in $\mathrm{Fe}$ storage, ferritins also play a role in preventing oxidative damage by storing free Fe in a safe form [49]. Our finding that $+\mathrm{Al} C$. sinensis roots had higher abundance of ferritin 1 agrees with the report that there was an increase in the expression of the ferritin Fe storage gene, AtFER1 in Pdeficient Arabidopsis leaves [50]. Nucleobase-ascorbate transporters (NATs) have been identified in prokaryotes, fungi, plants and mammals. In plants, maize leaf permease1 (ZmLPE1) has been characterized by functional complementation of a purine transport-deficient Aspergillus nidulans strain and is necessary for proper chloroplast development in maize. Interestingly, leaf permease1 protein does not contain a plastidic transit peptide and is expressed only in non-photosynthetic tissues such as roots and etiolated leaves [51]. The up-regulation of putative permease 1 in $+\mathrm{Al} C$. sinensis roots might be involved in Al-tolerance throught maintaing chloroplast morphology. Plant lipid transfer proteins (LTPs) are responsible for the shuttling of phospholipids and other fatty acid groups between cell membranes. Some LTPs with broad specificity are termed non-specific LTPs (nsLTPs). We found that the abundances of nsLTP2 and nsLTP-like protein decreased in + $\mathrm{Al} C$. grandis roots. This agrees with the reports that nsLTP (E30131) was up-regulated in Al-tolerant cultivar rice roots, and down-regulated in $\mathrm{Al}$-sensitive ones [52], that the expression levels of two genes encoding LTP-like proteins (DT045053 and DT045054) in wheat roots were higher in Al-tolerant than in Al-sensitive near isogenicline [53], and that mRNA levels of LTPs were higher in Al-tolerant than in Al-sensitive soybean genotype [31]. Similarly, putative phosphatidylglycerol/phosphatidylinositol transfer protein DDB_G0282179-like involved in lipid transport was increased in $+\mathrm{Al} C$. sinensis roots. However, Wang et al. [11] showed that Al-toxicity decreased the abundance of LTP in Al-tolerance rice roots, but did not signifaicantly affect its level in Al-sensitive ones. Taken all together, the ability of cell transport was enhanced in $+\mathrm{Al}$ roots, especially in $C$. sinensis, which might contribute to its higher Al-tolerance.

\section{Proteins involved in biological regulation and signal transduction}

Perception and transmission of stress signals by the cell play crucial roles in plant response to abiotic stresses. Protein kinases and phosphatases are the key players in cell signals. Here, we isolated five up-regulated proteins in phosphorylation (i.e., gi|1174718, gi|388325711, gi|25 5572716 and gi|255570037) and dephosphorylation (i.e., gi|75248508) in $+\mathrm{Al} C$. sinensis roots (Additional file 2), demonstrating that Al-toxicity triggered phosphorylationdependent signal transduction pathway in C. sinensis roots, which might be involved in its Al-tolerance. By contrast, two down-regulated (i.e., gi|6016428 and gi|52 077492) and two up-regulated (i.e., gi|33772201 and gi|255558866) proteins in phosphorylation and one upregulated protein in dephosphorylation (i.e., gi|75248508) were detected in $+\mathrm{Al}$ C. grandis roots (Additional file 2). This suggested that the balance between phosphorylation and dephosphorylation might be upset and phosphorylation of some proteins might be impaired in $+\mathrm{Al}$ C. grandis roots. Obviously, C. sinensis roots 
had a higher capacity to keep a better balance between phosphorylation and dephosphorylation than $C$. grandis ones under Al-toxicity, which might contribute to $C$. sinensis Al-tolerance.

Purple acid phosphatases (PAPs) play important roles in $\mathrm{P}$ acquisition and recycling in plants [54]. Wang et al. [11] observed that PAP1 expressed at a higher level in $\mathrm{Al}$-tolerant than in $\mathrm{Al}$-sensitive rice root, suggesting that Al-tolerant cultivar might relieve the Al-toxicity through improving the $\mathrm{P}$ acquisition. The higher up-regulation of PAP8 in $+\mathrm{Al} C$. sinensis than in $C$. grandis roots agrees with our report that the former might more effectively acquire $\mathrm{P}$ than the latter with or without Al-stress [19].

Plasma membrane-associated cation-binding protein 1 (PCaP1) is involved in intracellular signals through interaction with phosphatidylinositol phosphates and calmodulin [55]. Our finding that $+\mathrm{Al} C$. sinensis roots displayed higher abundance of $\mathrm{PCaP} 1$ (Additional file 2) agrees with the report that $\mathrm{Cu}$-stress indced the expression of PCaP1 in Arabidopsis [56].

Our finding that the level of putative G3BP-like protein-like, a protein involved in the Ras signal transduction pathway, was decreased only in $+\mathrm{Al} \mathrm{C.} \mathrm{grandis}$ roots (Additional file 2). This agrees with the report that the abundance of G3BP was up-regulated in wild Al-tolerant barley (XZ16) and unchanged in Al-tolerant barley cultivar (Dayton), and down-regulated in Alsensitive wild barley (XZ61) when exposed to Al-toxicity [15]. These results indicated that the down-regulation of G3BP might be associated with the lower Al-tolerance of C. grandis.

\section{Proteins involved in cell wall and cytoskeleton metabolism}

Plant cytoskeleton is highly dynamic networks of proteinaceous components consisting mainly of microtubules and microfilaments. Al-induced growth inhibition and swelling of roots demonstrated that plant cytoskeleton could be a target of Al-toxicity [57]. Studies showed that root microtubules and microfilaments were altered by $\mathrm{Al}$ toxicity $[57,58]$. In wheat, Al led to disorganization of actin filaments and formation of actin deposits [59]. As expected, we identified five down-regulated (i.e., gi|14 423860, gi|135444, gi|75250086, gi|241865168 and gi|195 976596) and two down-regulated (i.e., gi|297600120 and gi|59799374)] proteins related to cytoskeleton metabolism in C. sinensis and C. grandis roots, respectively. Apart from cytoskeleton proteins, we isolated two downregulated proteins (i.e., gi|449454512 and gi|22412 9194) in cell wall metabolism in $+\mathrm{Al} \mathrm{C}$. sinensis roots (Additional file 2). To conclude, Al-induced alterations in root cell wall and cytoskeleton metabolism differed between the both species.

\section{JA biosynthesis}

Phytohormones play a key role in plant response to (a)biotic stresses. Among these, one of the most important signal molecules is JA [60]. Here, we obtained four up-regulated proteins [i.e., two lipoxygenases (LOXs), long-chain acyl-CoA oxidase (ACX) and 12oxophytodienoate reductase 2 (OPR2)] involved in JA biosynthesis (Additional file 2; Fig. 5). LOX is one of the key enzymes responsible for the biosynthesis of JA. Al-induced up-regulation of LOX has also been reported in soybean [61] and Cassia tora [62, 63] roots. In Arabidopsis and rice, OPR3 and OPR 7 are responsible for JA production, respectively $[64,65]$. ACX catalyze the first step in the peroxisomal $\beta$ oxidation stage of JA biosynthesis. Wound-induced JA accumulation was reduced in a mutant that was defective in ACX1 and was abolished in a mutant that was impaired in both ACX1 and its closely related paralog, ACX5 [66]. Thus, both JA biosynthesis and level might be increased in $+\mathrm{Al} \mathrm{C}$. sinensis roots, thus enhancing plant Al-tolerance. Because LOX may increase the formation of oxidation products, Alinduced up-regulation of LOX has been suggested to be a response to Al-toxicity [61].

\section{Conclusions}

Our results demonstrate that $C$. sinensis is more tolerant to Al-toxicity than C. grandis. Using iTRAQ technique, we isolated 347 differentially expressed proteins from $+\mathrm{Al} C$. sinensis and C. grandis roots. Among these proteins, 202 proteins only presented in C. sinensis, 96 proteins only presented in $C$. grandis, and 49 proteins were shared by the two species. In the 49 overlapping proteins, 45 (4) proteins were regulated in the same (opposite) direction upon $\mathrm{Al}$ exposure. This indicated more remarkable metabolic flexibility in C. sinenis than in C. grandis roots, thus improving the Al-tolerance of $C$. sinensis. As shown in Fig. 7, the higher Al-tolerance of C. sinensis might be related to following several factors, including: (a) activation of $\mathrm{S}$ metabolism; (b) greatly improving the total ability of antioxidation and detoxification; (c) up-regulation of carbohydrate and energy metabolism; $(d)$ enhancing cell transport; $(e)$ decreasing (increasing) proteins related to protein synthesis (proteiolysis); ( $f$ ) maintaining a better balance between protein phosphorylation and dephosphorylation; and $(g)$ increasing JA biosynthesis. To sum up, we identified more differentially expressed proteins than those of previous studies in other plant roots and provided the most integrated view of the adaptive responses occurring in $+\mathrm{Al}$ roots. Therefore, our analysis of root Al-toxicity-responsive proteins will increase our understanding of Al-tolerant mechanisms in higher plants. 


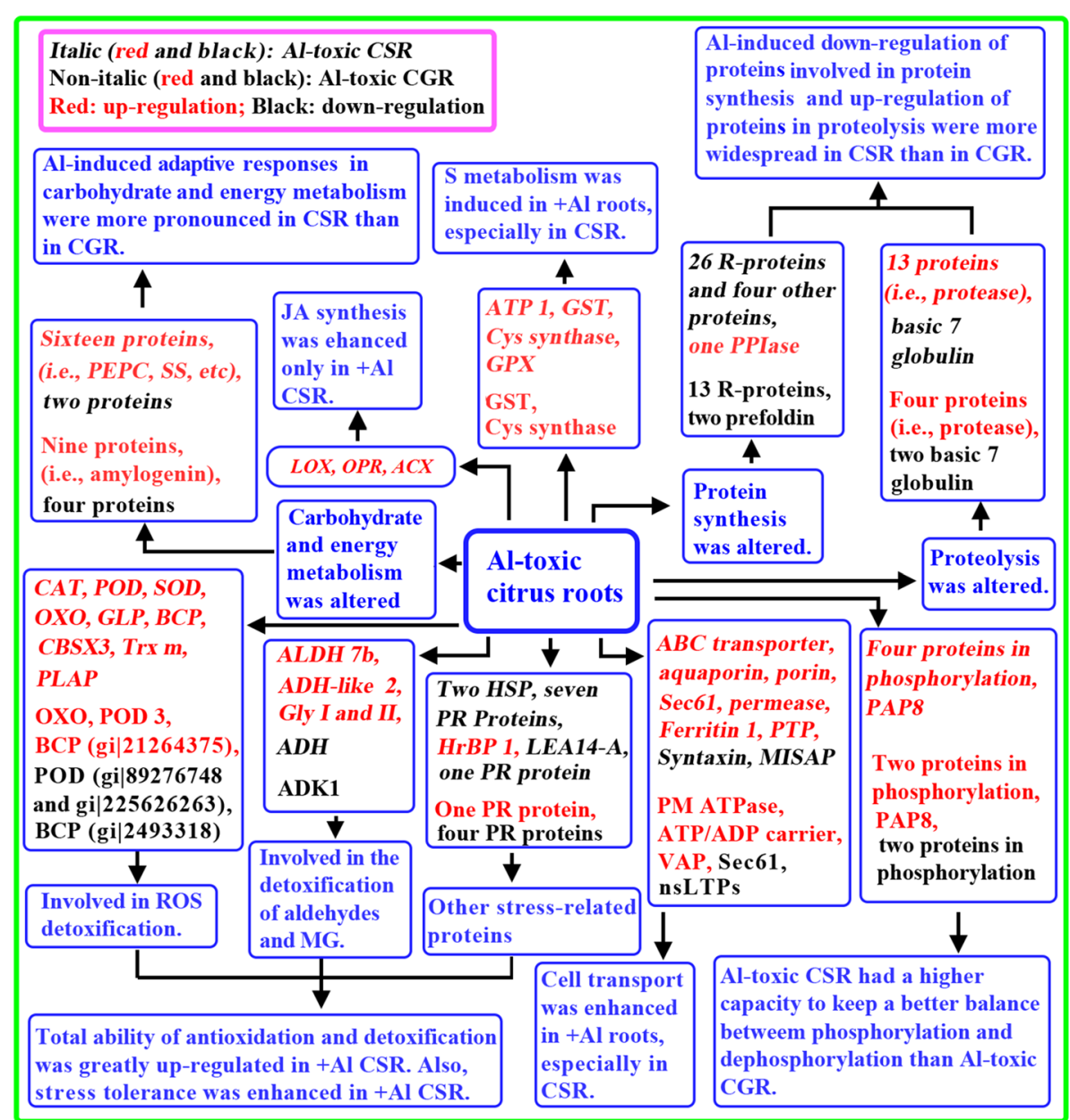

Fig. 7 A potential model for the adaptive responses of C. sinensis and C. grandis roots to Al-toxicity. CGR: C. grandis roots; CSR: C. sinensis roots; Gly: Glyoxalase; MISAP: Mitochondrial intermembrane space import and assembly protein; PEPC: Phosphoenolpyruvate carboxylase; PM ATPase: Plasma membrane $\mathrm{H}^{+}$-ATPase; PPlase: Peptidyl-prolyl cis-trans isomerase; PLAP: Plastid-lipid-associated protein; R-protein: Ribosomal protein; SS: Sucrose synthase; Trx m: Thioredoxin m; PTP: Phosphatidylglycerol/phosphatidylinositol transfer protein; VAP: Vesicle-associated protein

\section{Methods}

\section{Plant culture and Al treatments}

This study was conducted from February to December, 2012 at Fujian Agriculture and Forestry University, Fuzhou, China. Both plant culture and Al treatments were performed according to Jiang et al. [67] and Yang et al. [19]. Briefly, five-week-old uniform seedlings of 'Sour pummelo' [Citrus grandis (L.) Osbeck] and 'Xuegan' [Citrus sinensis (L.) Osbeck] with a single stem were selected and transplanted to $6 \mathrm{~L}$ pots containing fine river sand. Seedlings, two to a pot, were grown in a greenhouse under natural photoperiod. Each pot was supplied with $500 \mathrm{~mL}$ of nutrient solution every 2 days. The nutrient solution contained the following macronutrients (in mM): $\mathrm{KNO}_{3}, 1 ; \mathrm{Ca}\left(\mathrm{NO}_{3}\right)_{2}, 1 ; \mathrm{KH}_{2} \mathrm{PO}_{4}, 0.1$; and $\mathrm{MgSO}_{4}, 0.5$; and micronutrients (in $\mu \mathrm{M}$ ): $\mathrm{H}_{3} \mathrm{BO}_{3}, 20$; $\mathrm{MnCl}_{2}, 2 ; \mathrm{ZnSO}_{4}, 2 ; \mathrm{CuSO}_{4}, 0.5 ;\left(\mathrm{NH}_{4}\right)_{6} \mathrm{Mo}_{7} \mathrm{O}_{24}, 0.065$; and Fe-EDTA, 20. Six weeks after transplanting, each pot was supplied daily with a nutrient solution containing 0 (control) or $1.2 \mathrm{mM} \mathrm{AlCl} \cdot 6 \mathrm{H}_{2} \mathrm{O}(+\mathrm{Al})$ until the sand was saturated. The $\mathrm{pH}$ of the nutrient solutions was adjusted to $4.1-4.2$ using $\mathrm{HCl}$ or $\mathrm{NaOH}$. Eighteen weeks after the beginning of $\mathrm{Al}$ treatments, approx. 5-mm-long root apices from new white fibrous roots were excised and immediately frozen in liquid $\mathrm{N}_{2}$. Samples were stored at $-80{ }^{\circ} \mathrm{C}$ until extraction. The remaining seedlings that were not sampled were used to measure whole plant, root and shoot DWs and root $\mathrm{Al}$ concentration.

\section{Plant DWs and Al concentration in roots}

At the end of the experiment, 10 plants per treatment from different pots were harvested and divided into shoots (leaves + stems) and roots. Their DWs were measured after being dried at $70{ }^{\circ} \mathrm{C}$ for $48 \mathrm{~h}$.

Root $\mathrm{Al}$ concentration was determined colorimetrically by the aluminon after being digested in a 
mixture of $\mathrm{HNO}_{3}: \mathrm{HClO}_{4}$ [68]. There were six replicates per treatment.

\section{Protein extraction}

Proteins were extracted from frozen roots using a phenol extraction procedure according to Yang et al. [69]. Briefly, equal amounts of frozen root tips from six plants (one plant per pot) were mixed as a biological replicate. There was one biological replicates for each treatment. About $1 \mathrm{~g}$ frozen mixed samples were well ground in liquid $\mathrm{N}_{2}$ with a mortar and pestle. Four milliliter of ice-cooled buffer containing $100 \mathrm{mM}$ Tris- $\mathrm{HCl} \mathrm{pH} 7.8,100 \mathrm{mM} \mathrm{KCl}, 50 \mathrm{mM} \mathrm{L}-$ ascorbic acid, $1 \%(\mathrm{v} / \mathrm{v})$ Triton X-100, $1 \%(\mathrm{v} / \mathrm{v}) \beta-$ mercaptoethanol, and $1 \mathrm{mM}$ phenylmethanesulfonyl fluoride (PMSF) was added to the powder and gently pulverized. The mixture was allowed to thaw slowly on ice. The resulting suspension was transferred to a $10 \mathrm{~mL}$ tube, then an equal volume of Tris-phenol ( $\mathrm{pH}$ 8.0) was added. The mixture was thoroughly vortexed before centrifuging at $13000 \mathrm{~g}$ for $15 \mathrm{~min}$ at $4{ }^{\circ} \mathrm{C}$. The upper phenolic phase was transferred to a $50 \mathrm{~mL}$ tube, and then five volumes of $100 \mathrm{mM}$ ammonium acetate/methanol were added. After being mixed carefully, the mixture was stored at $-20{ }^{\circ} \mathrm{C}$ overnight. The supernatant was removed carefully after centrifugation at $13000 \mathrm{~g}$ for $15 \mathrm{~min}$ at $4{ }^{\circ} \mathrm{C}$, then the protein pellets were suspended in $25 \mathrm{~mL}$ of ice-cooled methanol for $2 \mathrm{~h}$ at $-20{ }^{\circ} \mathrm{C}$. Protein pellets were collected by centrifugation at $13000 \mathrm{~g}$ for $15 \mathrm{~min}$ at $4{ }^{\circ} \mathrm{C}$, and then were resuspended in $25 \mathrm{~mL}$ of ice-cooled acetone containing $0.1 \% \beta$-mercaptoethanol and kept at $-20{ }^{\circ} \mathrm{C}$ for $2 \mathrm{~h}$. After centrifugation at 13 $000 \mathrm{~g}$ for $15 \mathrm{~min}$ at $4{ }^{\circ} \mathrm{C}$, the pellets were washed twice with $25 \mathrm{~mL}$ of ice-cooled acetone, and then dried by lyophilization and finally stored at $-80{ }^{\circ} \mathrm{C}$ until use. Lyophilized protein samples were grinded to fine powder with pestle and liquid $\mathrm{N}_{2}$, then transferred to clean tubes and dissolved in lysis buffer [7 $\mathrm{M}$ urea, $2 \mathrm{M}$ thiourea, 4 \% 3-((3-cholamidopropyl)dimethylammonio)-1propanesulfonate (CHAPS), $40 \mathrm{mM}$ Tris- $\mathrm{HCl}, \mathrm{pH} 8.5$, $1 \mathrm{mM}$ PMSF and $2 \mathrm{mM}$ EDTA]. After $5 \mathrm{~min}, 10 \mathrm{mM}$ dithiothreitol (DTT) was added to the samples. The suspension was sonicated at $200 \mathrm{~W}$ for $15 \mathrm{~min}$ and then centrifuged at $4{ }^{\circ} \mathrm{C}, 30,000 \mathrm{~g}$ for $15 \mathrm{~min}$. The supernatant was mixed well with five volumes of chilled acetone containing $10 \%(\mathrm{v} / \mathrm{v})$ trichloracetic acid (TCA) and incubated at $-20{ }^{\circ} \mathrm{C}$ overnight. After centrifugation at $4{ }^{\circ} \mathrm{C}, 30,000 \mathrm{~g}$, the supernatant was discarded. The precipitate was washed with chilled acetone three times. The pellet was air-dried and dissolved in lysis buffer [7 $\mathrm{M}$ urea, $2 \mathrm{M}$ thiourea, $4 \%$ Tergitol-type NP40 (NP40), $20 \mathrm{mM}$ Tris-HCl, pH 8.0-8.5]. The suspension was sonicated at $200 \mathrm{~W}$ for $15 \mathrm{~min}$ and centrifuged at
$4{ }^{\circ} \mathrm{C}, 30,000 \mathrm{~g}$ for $15 \mathrm{~min}$. The supernatant was transferred to another tube. To reduce disulfide bonds in proteins of the supernatant, $10 \mathrm{mM}$ DTT was added and incubated at $56{ }^{\circ} \mathrm{C}$ for $1 \mathrm{~h}$. Subsequently, $55 \mathrm{mM}$ idoacetamide (IAM) was added to block the cysteines, incubated for $1 \mathrm{~h}$ in the dark room. The supernatant was mixed well with 55 volumes of chilled acetone for $2 \mathrm{~h}$ at $-20{ }^{\circ} \mathrm{C}$ to precipitate proteins. After centrifugation at $4{ }^{\circ} \mathrm{C}, 30,000 \mathrm{~g}$, the supernatant was discarded, and the pellet was air-dried for $5 \mathrm{~min}$, dissolved in $500 \mu \mathrm{L} 0.5 \mathrm{M}$ tetraethylammonium bromide (TEAB), and sonicated at $200 \mathrm{~W}$ for $15 \mathrm{~min}$. Finally, samples were centrifuged at $4{ }^{\circ} \mathrm{C}, 30,000 \mathrm{~g}$ for $15 \mathrm{~min}$. The supernatant was transferred to a new tube and quantified using a Bio-Rad Protein Assay kit based on the Bradford method using bovine serum albumin as a standard. The proteins in the supernatant were kept at $-80{ }^{\circ} \mathrm{C}$ for further analysis.

\section{ITRAQ analysis and bioinformatic analysis of proteins}

iTRAQ analysis was implemented at Beijing Genomics Institute (BGI, Shenzhen, China).

One-hundred $\mu \mathrm{g}$ protein was taken out of Al-toxic and control sample solution and then the protein was digested with Trypsin Gold (Promega, Madison, WI, USA) with the ratio of protein : trypsin $=30: 1$ at $37^{\circ}$ $\mathrm{C}$ for $16 \mathrm{~h}$. After trypsin digestion, peptides were dried by vacuum centrifugation. Peptides were reconstituted in $0.5 \mathrm{M} \mathrm{TEAB}$ and processed according to the manufacture's protocol for 8-plex iTRAQ reagent (AB Sciex Inc., MA, USA). Briefly, one unit of iTRAQ reagent was thawed and reconstituted in $24 \mu \mathrm{L}$ isopropanol. Al-toxic and control samples for $C$. sinensis $(C$. grandis) were labeled with 118 and 119 (115 and 117) tags, respectively. The peptides labeled with the isobaric tags were incubated at room temperature for $2 \mathrm{~h}$. The labeled peptide mixtures were then pooled and dried by vacuum centrifugation.

For strong cationic exchange (SCX) chromatography using a Shimadzu LC-20AB HPLC Pump system (Shimadzu Co. Kyoto, Japan), the iTRAQ-labeled peptide mixtures were redissolved in $4 \mathrm{~mL}$ of buffer $\mathrm{A}$ [ $25 \mathrm{mM} \mathrm{NaH}_{2} \mathrm{PO}_{4}$ in $25 \%$ acetonitrile (CAN), pH 2.7] and loaded onto a $4.6 \times 250 \mathrm{~mm}$ Ultremex SCX column. The peptides were eluted at a flow rate of $1 \mathrm{~mL} \mathrm{~min}^{-1}$ with a linear gradient of $5 \%$ buffer B $\left(25 \mathrm{mM} \mathrm{NaH}_{2} \mathrm{PO}_{4}\right.$ and $1 \mathrm{M} \mathrm{KCl}$ in $25 \% \mathrm{ACN}, \mathrm{pH} 2.7$ ) for $7 \mathrm{~min}, 5-60 \%$ buffer B for 20 min and $60-100 \%$ buffer B for 2 min and maintained in $100 \%$ buffer B for 1 min before equilibrating with buffer $\mathrm{B}$ for $10 \mathrm{~min}$ prior to the next injection. Elution was monitored by measuring the absorbance at $214 \mathrm{~nm}$. The eluted peptides were pooled as 20 fractions, desalted by $\mathrm{C}-18$ coloum and vacuum dried. 
Each fraction was resuspended in a certain volume of buffer C (5 \% ACN, $0.1 \%$ formic acid) and centrifuged at $20000 \mathrm{~g}$ for $10 \mathrm{~min}$. In each fraction, the final concentration of peptide was ca. $0.5 \mu \mathrm{g} \mu \mathrm{L}^{-1}$. A total of $5 \mu \mathrm{L}$ of supernatant was loaded onto a Shimadzu LC20 AD nanoHPLC (Shimadzu Co. Kyoto, Japan) by the autosampler onto a $2 \mathrm{~cm} \mathrm{C18}$ trap column (inner diameter, $200 \mu \mathrm{m}$ ), and the peptides were eluted onto a resolving $10 \mathrm{~cm}$ analytical C18 column (inner diameter, $75 \mu \mathrm{m})$. The samples were loaded at $8 \mu \mathrm{L} \mathrm{min}{ }^{-1}$ for $4 \mathrm{~min}$; then eluted at $300 \mathrm{~nL} \mathrm{~min}{ }^{-1}$ with a linear grandent of $5 \%$ buffer D ( $95 \% \mathrm{ACN}, 0.1 \%$ formic acid) for $5 \mathrm{~min}$, 3-35 \% buffer D for $35 \mathrm{~min}, 35-60 \%$ buffer D for $5 \mathrm{~min}$, $60-80 \%$ buffer D for $2 \mathrm{~min}$ and maintained in $80 \%$ buffer $\mathrm{D}$ for $2 \mathrm{~min}$, finally returned to $5 \%$ buffer D within $1 \mathrm{~min}$ and maintained in $5 \%$ buffer D for $10 \mathrm{~min}$.

For the TripleTOF analysis, a TripleTOF 5600 system 5600 (AB SCIEX, Concord, ON, Canada) fitted with a Nanospray III source and a pulled quartz tip as the emitter was used. Data were acquired using an ion spray voltage of $2.5 \mathrm{kV}, \mathrm{N}$ gas of $30 \mathrm{psi}$, nebulizer gas of $15 \mathrm{psi}$, and an interface heater temperature of $150{ }^{\circ} \mathrm{C}$. The MS was operated with an RP of $\geq 30,000$ FWHM for TOF-MS scans. For information dependent acquisition (IDA), survey scans were acquired in $250 \mathrm{~ms}$ and as many as 30 product ion scans were collected if they exceeded a threshold of $120 \mathrm{cps}$ with a $2^{+}$to $5^{+}$chargestate. The total cycle time was fixed to $3.3 \mathrm{~s}$ and the Q2 transmission window was $100 \mathrm{Da}$ for $100 \%$. Four time bins were summed for each scan at a pulser frequency value of $11 \mathrm{kHz}$ through monitoring of the $40 \mathrm{GHz}$ multichannel TDC detector with four-anode/channel detection. A sweeping collision energy setting of $35 \pm 5 \mathrm{eV}$ coupled with iTRAQ adjust rolling collision energy was applied to all precursor ions for collision-induced dissociation. Dynamic exclusion was set for $1 / 2$ of peak width (15 s), and then the precursor was refreshed off the exclusion list.

Raw data files acquired from the TripleTof were converted into MGF files using Proteome Discoverer 1.2 and the MGF files were searched. Proteins identification was performed by using Mascot search engine (Version 2.3.02; Matrix Science, London, UK) against C. sinensis database (http://www.phytozome.net/cgibin/gbrowse/citrus/). For protein identification, a mass tolerance of \pm 0.05 Da was permitted for intact peptide masses and $\pm 0.1 \mathrm{Da}$ for fragmented ions, with allowance for one missed cleavages in the trypsin digests. Pyrophosphorylation of glutamine and variable oxidation of methionine and iTRAQ labeling of tyrosine were set as variable modification; carbamidomethylation of Cys and iTRAQ labeling of lysine the $\mathrm{N}$-terminal amino group of peptides were set as fixed modification. The peptide charge was set as $M r$, and monoisotopic mass was chosen. To decrease the probability of false peptide identification, only peptides with significance scores $(\geq 20)$ at the $99 \%$ confidence interval by a Mascot probability analysis greater than "identity" were counted as identified. Each confident protein identification included at least one unique peptide. An automatic decoy database search strategy was used to estimate the false discovery rate (FDR), which was calculated as the false positive matches divided by the total matches. In the final search results, the FDR was less than $1.5 \%$. The iTRAQ 8-plex was chosen for quantification during the search.

The search results were filtered before data exportation. The filters were used for protein identification with these options: significance threshold $P<0.05$ (with $95 \%$ confidence) and ion score or expected cut-off less than 0.05 (with $95 \%$ confidence). For protein quantitation, the filters were set as follows: (a) "median" was chosen for the protein ratio type; $(b)$ the minimum precursor charge was set to 2 and minimum peptides were set to 2 , and only unique peptides were used for quantitation; and $(c)$ normalization by median intensities, and outliers were removed automatically. The peptide threshold was set as above for identity. A $1.5 \log 2$-fold change was set to identify significant differentially expressed proteins in addition with a $P$-value of less than 0.05 . Distribution fitting of protein ratios data was performed using SPSS software. The two protein datasets were fitted into Normal distribution models and the threshold for significance of $+/-1.5$ was sufficient to separate differentially expressed proteins.

Bioinformatic analysis of proteins was performed according to Yang et al. [69].

\section{Quantitative RT-PCR (qRT-PCR) analysis of gene expression}

Root tips of six plants from different pots were mixed as a biological replicate. Equal amounts of root tips were collected from each plant. There were three biological replicates for each treatment. Total RNAs were independently extracted three times from the frozen roots of Al-toxic and control plants using Recalcirtant Plant Total RNA Extraction Kit (Centrifugal column type, Bioteke Corporation, China) according to manufacturer's instructions. Gene-specific primers were designed using Primer Software Version 5.0 (PREMIER Biosoft International, CA, USA) according to the corresponding sequences of selected proteins in Citrus genome (http://www.phytozome.net/cgi-bin/gbrowse/ citrus/). The sequences of the $\mathrm{F}$ and $\mathrm{R}$ primers used are given in Additional file 3. qRT-PCR analysis was performed according to Zhou et al. [70]. For the normalization of gene expression, $\beta$-tubulin (JN580571) gene was used as an internal standard and the roots from control plants were used as reference sample, which was set to 1 . 


\section{Experimental design and statistical analysis}

There were 40 seedlings ( 20 pots) in a completely randomized design. Experiments were performed with 3-10 replicates except for iTRAQ analysis (i.e., one biological replicate). The replicates represented material from individual plant except for iTRAQ and qRT-PCR analysis [i.e., each biological replicate was created by pooling equal roots from six different plants (one plant per pot)]. Differences among four treatment combinations were analyzed by 2 (species) $\times 2$ (Al levels) ANOVA. The unpaired $t$-test was applied for comparison between two means (i.e., qRT-PCR data). Power analysis was performed by using pwr.t.test functions of pwr.package in $\mathrm{R}$ environment (Version 3.2.0). Under empirical $\mu$ and $\sigma$, the minimum sample size of 8 and 3 could generate a power value of more than 0.8 in plant DW measurement and the other experiments, respectively.

\section{Availability of supporting data}

The mass spectrometry proteomics data have been deposited to the ProteomeXchange Consortium via the PRIDE partner repository with the dataset identifier PXD002301.

\section{Additional files}

Additional file 1: Effects of Al-toxicity on plant growth and root Al concentration in Citrus sinensis and $C$. grandis seedlings. (DOC $184 \mathrm{~kb})$

Additional file 2: List of differentially expressed proteins in Al-toxicity Citrus sinensis (CS) and C. grandis (CG) roots. (DOC $418 \mathrm{~kb}$ )

Additional file 3: Specific primer pairs used for qRT-PCR expression analysis. (DOC $40 \mathrm{~kb}$ )

\begin{abstract}
Abbreviations
12,13-EOT: 12,13-epoxyoctadecatrienoic acid; 13-HPOT: (13S)hydroperoxyoctadecatrienoic acid; 2-DE: Two-dimensional gel electrophoresis; ABC: ATP Binding Cassette; ACC: 1-aminocydopropane1-carboxylate; ACX: Aacyl-CoA-oxidase; ADH: Alcohol dehydrogenase; AKR: Aldo-keto reductase; Al: Aluminum; ALDH: Aldehyde dehydrogenase; AOC: Allene oxide cyclase; AOS: Allene oxide synthase; APX: Ascorbate peroxidase; ATPS: ATP sulfurylase; BCP: Blue copper protein;

CAT: Catalase; cis-(+)-OPDA: cis-(+)-12-oxophytodienoic acid; Cu/Zn SOD: Copper/zinc superoxide dismutase; DHAR: dehydroascorbate reductase; DW: Dry weight; GAD: Glutamate decarboxylase; GLP: Germin and germin-like protein; Gly: Glyoxalase; GPX: Glutathione peroxidase; GR: Glutathione reductase; GSH: Reduced glutathione; GSSG: Oxidized glutathione; GST: Glutathione S-transferase; HSP: Heat shock protein; ITRAQ: Isobaric tags for relative and absolute quantification; JA: Jasmonic acid; LEA: Late embryogenesis abundant protein; LOX: Lipoxygenase; LTP: Lipid transfer protein; MDA: Malondialdehyde; MDH: Malate dehydrogenase; MG: Methylglyoxal; MLP: Major latex protein; NAT: Nucleobase-ascorbate transporter; NiR: Nitrite reductase; nsLTP: Non-specific LTP; OPC-8: 3-oxo-2-(2'(Z)-pentenyl)-cyclopentane-1-octanoic acid; OPR: Oxophytodienoic acid reductase; OXO: Oxalate oxidase; PAL: Phenylalanine ammonia-lyase; PAP: Purple acid phosphatase; POD: Peroxidase; PTM: Post-translational modification; ROS: reactive oxygen species; S: sulfur; SA: Salicylic acid.
\end{abstract}

\section{Competing interests}

The authors declare that they have no competing interests.

\section{Authors' contributions}

H.X.J and L.T.Y. contributed equally as first author. H.X.J carried out bioinformatic analysis of proteins and drafted the manuscript. L.T.Y extracted the proteins, carried out the qRT-PCR analysis, and participated in the design of the study. Y.P.Q. participated in the design of the study. Y.B.L. carried out the cultivation of seedlings. Z.R.H. carried out the analysis of Al. L.S.C. designed and directed the study and revised the manuscript. All authors have read and approved the final manuscript.

\section{Acknowledgements}

This work was supported by the Specialized Research Fund for the Doctoral Program of Higher Education of China (No. 20123515110017) and the earmarked fund for China Agriculture Research System (No. CARS-27).

\section{Author details}

${ }^{1}$ Institute of Plant Nutritional Physiology and Molecular Biology, Fujian Agriculture and Forestry University, Fuzhou 350002, China. ${ }^{2}$ College of Life Science, Fujian Agriculture and Forestry University, Fuzhou 350002, China. ${ }^{3}$ College of Resource and Environmental Science, Fujian Agriculture and Forestry University, Fuzhou 350002, China. ${ }^{4}$ Institute of Materia Medica, Fujian Academy of Medical Sciences, Fuzhou 350001, China. ${ }^{5}$ The Higher

Educational Key Laboratory of Fujian Province for Soil Ecosystem Health and Regulation, Fujian Agriculture and Forestry University, Fuzhou 350002, China.

${ }^{6}$ Fujian Key Laboratory for Plant Molecular and Cell Biology, Fujian

Agriculture and Forestry University, Fuzhou 350002, China.

Received: 23 June 2015 Accepted: 23 October 2015

Published online: 16 November 2015

\section{References}

1. von Uexküll HR, Mutert E. Global extent, development and economic impact of acid soils. In: Date RA, Grundon NJ, Raymet GE, editors. Plant-Soil Interactions at Low pH: Principles and Management. Dordrecht: Kluwer Academic Publishers; 1995. p. 5-19.

2. Yang LT, Qi YP, Jiang HX, Chen LS. Roles of organic acid anion secretion in aluminium tolerance of higher plants. BioMed Res Int. 2013;2013:173682.

3. Kochian LV, Hoekenga OA, Piñeros MA. How do crop plants tolerate acid soils? Mechanisms of aluminum tolerance and phosphorus efficiency. Ann Rev Plant Biol. 2004;55:459-93.

4. Yang Q, Wang Y, Zhang J, Shi W, Qian C, Peng X. Identification of aluminum-responsive proteins in rice roots by a proteomic approach: cysteine synthase as a key player in Al response. Proteomics. 2007;7:737-49.

5. Ma JF. Syndrome of aluminum toxicity and diversity of aluminum resistance in higher plants. Int Rev Cytol. 2007;264:225-52.

6. Liu J, Piñeros MA, Kochian LV. The role of aluminum sensing and signaling in plant aluminum resistance. J Integr Plant Biol. 2014;56:221-30.

7. Chandran D, Sharopova N, Ivashuta S, Gantt JS, Vandenbosch KA, Samac DA. Transcriptome profiling identified novel genes associated with aluminum toxicity, resistance and tolerance in Medicago runcatula. Planta. 2008;228:151-66

8. Fan W, Lou HQ, Gong YL, Liu MY, Wang ZQ, Yang JL, et al. Identification of early Al-responsive genes in rice bean (Vigna umbellata) roots provides new clues to molecular mechanisms of Al toxicity and tolerance. Plant Cell Environ. 2014;37:1586-97

9. Zhou XX, Yang LT, Qi YP, Guo P, Chen LS. Mechanisms on boron-induced alleviation of aluminum-toxicity in Citrus grandis seedlings at a transcriptional level revealed by CDNA-AFLP analysis. PLOS ONE. 2015;10:e0115485.

10. Hossain Z, Komatsu S. Contribution of proteomic studies towards understanding plant heavy metal stress response. Front Plant Sci. 2013:3:310.

11. Wang ZQ, Xu XY, Gong QQ, Xie C, Fan W, Yang JL, et al. Root proteome of rice studied by ITRAQ provides integrated insight into aluminum stress tolerance mechanisms in plants. J Proteomics. 2014:98:189-205.

12. Zhen Y, Qi JL, Wang SS, Su J, Xu GH, Zhang MS, et al. Comparative proteome analysis of differentially expressed proteins induced by Al toxicity in soybean. Physiol Plant. 2007;131:542-54.

13. Duressa D, Soliman K, Taylor R, Senwo Z. Proteomic analysis of soybean roots under aluminum stress. Int J Plant Genomics. 2011;2011:282531.

14. Zhou S, Sauvé R, Thannhauser TW. Proteome changes induced by aluminium stress in tomato roots. J Exp Bot. 2009;60:1849-57. 
15. Dai H, Cao F, Chen X, Zhang M, Ahmed IM, Chen ZH, et al. Comparative proteomic analysis of aluminum tolerance in Tibetan wild and cultivated barleys. PLOS ONE. 2013;8, e63428.

16. Oh MW, Roy SK, Kamal AH, Cho K, Cho SW, Park CS, et al. Proteome analysis of roots of wheat seedlings under aluminum stress. Mol Biol Rep. 2014;41:671-81.

17. Li Y, Han MQ, Lin F, Ten Y, Lin J, Zhu DH, Guo P, Weng YB, Chen LS. Soil chemical properties, 'Guanximiyou' pummelo leaf mineral nutrient status and fruit quality in the southern region of Fujian province. China. J Soil Sci Plant Nutr. 2015;15:615-28.

18. Lin Z, Myhre DL. Citrus root growth as affected by soil aluminum level under field conditions. Soil Sci Soc Amer J. 1990;54:1340-4.

19. Yang LT, Jiang HX, Tang N, Chen LS. Mechanisms of aluminum-tolerance in two species of Citrus: secretion of organic acid anions and immobilization of aluminum by phosphorus in roots. Plant Sci. 2011;180:521-30.

20. Yang LT, Jiang HX, Qi YP, Chen LS. Differential expression of genes involved in alternative glycolytic pathways, phosphorus scavenging and recycling in response to aluminum and phosphorus interactions in Citrus roots. Mol Biol Rep. 2012:39:6353-66.

21. Ezaki B, Gardner RC, Ezaki Y, Matsumoto H. Expression of aluminum-induced genes in transgenic Arabidopsis plants can ameliorate aluminum stress and/ or oxidative stress. Plant Physiol. 2000;127:918-27.

22. Dixit P, Mukherjee PK, Ramachandran V, Eapen S. Glutathione transferase from Trichoderma virens enhances cadmium tolerance without enhancing its accumulation in transgenic Nicotiana tabacum. PLOS ONE. 2011;6, e16360.

23. Yoshimura K, Miyao K, Gaber A, Takeda T, Kanaboshi H, Miyasaka H, et al. Enhancement of stress tolerance in transgenic tobacco plants overexpressing Chlamydomonas glutathione peroxidase in chloroplasts or cytosol. Plant J. 2004;37:21-33.

24. Navrot N, Collin V, Gualberto J, Gelhaye E, Hirasawa M, Rey P, et al. Plant glutathione peroxidases are functional peroxiredoxins distributed in severa subcellular compartments and regulated during biotic and abiotic stresses. Plant Physiol. 2006;142:1364-79.

25. Chen LS, Qi YP, Liu XH. Effects of aluminum on light energy utilization and photoprotective systems in Citrus leaves. Ann Bot. 2005;96:35-41.

26. Dunwell JM, Gibbings JG, Mahmood T, Naqvi SMS. Germin and germin-like proteins: evolution, structure, and function. Crit Rev Plant Sci. 2008:27:342-75.

27. Li HY, Jiang J, Wang S, Liu FF. Expression analysis of ThGLP, a new germin-like protein gene, in Tamarix hispida. J For Res. 2010;21:323-30

28. Delisle G, Champoux M, Houde M. Characterization of oxalate oxidase and cell death in Al-sensitive and tolerant wheat roots. Plant Cell Physiol. 2001;42:324-33.

29. Karuppanapandian T, Rhee SJ, Kim EJ, Han BK, Hoekenga OA, Lee GP. Proteomic analysis of differentially expressed proteins in the roots of Columbia-0 and Landsberg erecta ecotypes of Arabidopsis thaliana in response to aluminum-toxicity. Can J Plant Sci. 2012;92:1267-82.

30. Hanin M, Brini F, Ebel C, Toda Y, Takeda S, Masmoudi K. Plant dehydrins and stress tolerance: versatile proteins for complex mechanisms. Plant Signal Behav. 2011;6:1503-9.

31. Duressa D, Soliman KM, Taylor RW, Chen DQ. Gene expression profiling in soybean under aluminum stress: genes differentially expressed between Al-tolerant and Al-sensitive genotypes. Am J Mol Biol. 2011;1:156-73.

32. Zhang L, Xiao S, Li W, Feng W, Li J, Wu Z, et al. Overexpression of a Harpin-encoding gene hrf1 in rice enhances drought tolerance. J Exp Bot. 2011;62:4229-38.

33. Wei ZM, Laby RJ, Zumoff CH, Bauer DW, He SY, Collmer A, et al. Harpin, elicitor of the hypersensitive response produced by the plant pathogen Erwinia amylovora. Science. 1992;257:85-8.

34. Stobrawa K, Lorenc-Plucińska G. Changes in carbohydrate metabolism in fine roots of the native European black poplar (Populus nigra L.) in a heavy-metal-polluted environment. Sci Total Environ. 2007;373:157-65.

35. Xiao XX, Liu XH, Yang ZW, Wan Q, Zheng R, Wan ZJ. Effect of aluminum stress on the content of protein and nucleic acid of longan (Dimocarpus longan) seedlings. Scientia Sinvae Sinicae. 2006;42(10):24-30.

36. Kumari M, Taylor GJ, Deyholos MK. Transcriptomic responses to aluminum stress in roots of Arabidopsis thaliana. Mol Genet Genomics. 2008:279:339-57.

37. Araújo WL, Tohge T, Ishizaki K, Leaver CJ, Fernie AR. Protein degradation-an alternative respiratory substrate for stressed plants. Trends Plant Sci. 2011;16:489-98.
38. Schultz CJ, Hsu M, Miesak B, Coruzzi GM. Arabidopsis mutants define an in vivo role for isoenzymes of aspartate aminotransferase in plant nitrogen assimilation. Genetics. 1998;149:491-9.

39. Goyer A, Johnson TL, Olsen LJ, Collakova E, Shachar-Hill Y, Rhodes D, et al Characterization and metabolic function of a peroxisomal sarcosine and pipecolate oxidase from Arabidopsis. J Biol Chem. 2004;279:16947-53.

40. Wang S, Wang L, Zhou Q, Huang X. Combined effect and mechanism of acidity and lead ion on soybean biomass. Biol Trace Elem Res. 2013;156:298-307.

41. Bouché N, Fait A, Zik M, Fromm H. The root-specific glutamate decarboxylase (GAD1) is essential for sustaining GABA levels in Arabidopsis. Plant Mol Biol. 2004;55:315-25.

42. Oh SH, Choi WG, Lee IT, Yun SJ. Cloning and characterization of a rice cDNA encoding glutamate decarboxylase. J Biochem Mol Biol. 2005;38:595-601.

43. Rea P. MRP subfamily ABC transporters from plants and yeast. J Exp Bot 1999:50:895-913

44. Larsen PB, Geisler MJB, Jones CA, Williams KM, Cancel JD. ALS3 encodes a phloem-localized $A B C$ transporter-like protein that is required for aluminum tolerance in Arabidopsis. Plant J. 2005:41:353-63.

45. Maurel C, Santoni V, Luu DT, Wudick MM, Verdoucq L. The cellular dynamics of plant aquaporin expression and functions. Curr Opin Plant Biol. 2009;12:690-8

46. Shen H, Chen J, Wang Z, Yang C, Sasaki T, Yamamoto Y, et al. Root plasma membrane $\mathrm{H}^{+}$-ATPase is involved in the adaptation of soybean to phosphorus starvation. J Exp Bot. 2006:57:1353-62.

47. Linka N, Weber AP. Intracellular metabolite transporters in plants. Mol Plant. 2010:3:21-53.

48. Coleman CE, Lopes MA, Gillikin JW, Boston RS, Larkins BA. A defective signal peptide in the maize high-lysine mutant floury 2. Proc Natl Acad Sci U S A. 1995;92:6828-31.

49. Briat JF, Ravet K, Arnaud N, Duc C, Boucherez J, Touraine B. New insights into ferritin synthesis and function highlight a link between iron homeostasis and oxidative stress in plants. Ann Bot. 2010;105:811-22.

50. Misson J, Raghothama KG, Jain A, Jouhet J, Block MA, Bligny R, et al. A genome-wide transcriptional analysis using Arabidopsis thaliana Affymetrix gene chips determined plant responses to phosphate deprivation. Proc Natl Acad Sci U S A. 2005;102:11934-9.

51. Schultes NP, Brutnell TP, Allen A, Dellaporta SL, Nelson T, Chen J. Leaf permease 1 gene of maize is required for chloroplast development. Plant Cell. 1996:8:463-70

52. Mao CZ, Yang L, Zheng BS, Wu YR, Liu FY, Yi KK, et al. Comparative mapping of QTLs for Al tolerance in rice and identification of positional Al-induced genes. J Zhejiang Univ (Sci). 2004;5:634-43.

53. Guo P, Bai G, Carver B, Li R, Bernardo A, Baum M. Transcriptional analysis between two wheat near-isogenic lines contrasting in aluminum tolerance under aluminum stress. Mol Genet Genomics. 2007;277:1-12.

54. Kaida R, Serada S, Norioka N, Norioka S, Neumetzler L, Pauly M, et al. Potential role for purple acid phosphatase in the dephosphorylation of wall proteins in tobacco cells. Plant Physiol. 2010;153:603-10.

55. Kato M, Nagasaki-Takeuchi N, Ide Y, Tomioka R, Maeshima M. PCaPs, possible regulators of PtdlnsP signals on plasma membrane. Plant Signal Behav. 2010;5:848-50.

56. Ide Y, Nagasaki N, Tomioka R, Suito M, Kamiya T, Maeshima M. Molecular properties of a novel, hydrophilic cation-binding protein associated with the plasma membrane. J Exp Bot. 2007;58:1173-83.

57. Blancaflor EB, Jones DL, Gilroy S. Alterations in the cytoskeleton accompany aluminum-induced growth inhibition and morphological changes in primary roots of maize. Plant Physiol. 1998;118:159-72.

58. Amenós M, Corrales I, Poschenrieder C, Illéš P, Baluška F. Different effects of aluminum on the actin cytoskeleton and brefeldin a-sensitive vesicle recycling in root apex cells of two maize varieties differing in root elongation rate and aluminum tolerance. Plant Cell Physiol. 2009;50:528-40.

59. Frantzios G, Galatis B, Apostolakos P. Aluminium causes variable responses in actin filament cytoskeleton of the root tip cells of Triticum turgidum Protoplasma. 2005:225:129-40.

60. Santino A, Taurino M, De Domenico S, Bonsegna S, Poltronieri P, Pastor V, et al. Jasmonate signaling in plant development and defense response to multiple (a)biotic stresses. Plant Cell Rep. 2013;32:1085-98.

61. You J, Zhang H, Liu N, Gao L, Kong L, Yang Z. Transcriptomic responses to aluminum stress in soybean roots. Genome. 2011;54:923-33. 
62. Wang YS, Yang ZM. Nitric oxide reduces aluminum toxicity by preventing oxidative stress in the roots of Cassia tora L. Plant Cell Physiol. 2005;46:1915-23.

63. Xue YJ, Tao L, Yang ZM. Aluminum-induced cell wall peroxidase activity and lignin synthesis are differentially regulated by jasmonate and nitric oxide. J Agric Food Chem. 2008;56:9676-84.

64. Schaller F, Biesgen C, Müssig C, Altmann T, Weiler EW. 12-Oxophytodienoate reductase 3 (OPR3) is the isoenzyme involved in jasmonate biosynthesis. Planta. 2000;210:979-84.

65. Tani T, Sobajima H, Okada K, Chujo T, Arimura S, Tsutsumi N, et al Identification of the OsOPR7 gene encoding 12-oxophytodienoate reductase involved in the biosynthesis of jasmonic acid in rice. Planta. 2008;227:517-26.

66. Schilmiller AL, Koo AJ, Howe GA. Functional diversification of acyl-coenzyme A oxidases in jasmonic acid biosynthesis and action. Plant Physiol. 2007; 143:812-24

67. Jiang HX, Tang N, Zheng JG, Li Y, Chen LS. Phosphorus alleviates aluminuminduced inhibition of growth and photosynthesis in Citrus grandis seedlings. Physiol Plant. 2009;137:298-311.

68. Hsu PH. Effect of initial pH, phosphate, and silicate on the determination of aluminum with aluminon. Soil Sci. 1963;96:230-8.

69. Yang LT, Qi YP, Lu YB, Gu P, Sang W, Feng H, et al. iTRAQ protein profile analysis of Citrus sinensis roots in response to long-term boron-deficiency. J Proteomics. 2013;93:179-206.

70. Zhou CP, Qi YP, You X, Yang LT, Guo P, Ye X, et al. Leaf cDNA-AFLP analysis of two Citrus species differing in manganese tolerance in response to long-term manganese-toxicity. BMC Genomics. 2013;14:621.

\section{Submit your next manuscript to BioMed Central and take full advantage of:}

- Convenient online submission

- Thorough peer review

- No space constraints or color figure charges

- Immediate publication on acceptance

- Inclusion in PubMed, CAS, Scopus and Google Scholar

- Research which is freely available for redistribution 